\title{
THE INFLUENCE OF CORPORATE SOCIAL RESPONSIBILITY ON AN EMPLOYEE'S SENSE OF BELONGING
}

\author{
BY \\ NATHALIE WEERASUNDARA \\ A thesis \\ submitted to the Victoria University of Wellington \\ In partial fulfilment of the requirements for the degree of \\ Master of Commerce
}

Victoria University of Wellington

2015 


\title{
The Influence of Corporate Social Responsibility on an Employee's Sense of Belonging
}

\author{
Nathalie Weerasundara
}

\section{ABSTRACT}

Corporate Social Responsibility (CSR) has increasingly become identified as a societal expectation of companies around the world. The concept has not only risen in significance, but its impacts and potential benefits have become widely recognised by the organisational literature as well as managers. As a result, the influence of CSR practices have been discussed in regards to the numerous stakeholders that hold a vested interest in a company. However, the literature has been predominantly focused on the influence of CSR on external stakeholders such as: shareholders, customers, Non-Governmental Organisations (NGOs) and the general public. As such, the attention attributed to the internal stakeholder group of employees, has been relatively underdeveloped. While focus on this area has begun to emerge throughout the literature, there continues to be a lack of attention given to the effects of CSR on an individual's sense of belonging within the organisation. As a result, there is a lack of understanding on the nature and extent of this relationship within the existing literature.

This qualitative, interview-based study of fourteen respondents, presents results that provide a greater understanding of the relationship between CSR and an individual employee's sense of belonging. The results uncover the consequences of an organisation's CSR initiatives on its employees and discusses its influence over fostering a sense of belonging. The findings illustrate that significant impacts upon an employee's sense of belonging include generating a sense of pride in the organisation, promoting bottom-up, employee-driven initiatives and establishing social relationships amongst colleagues. The findings also recognise the similarly unexplored potential for this influence on employee belonging to be negatively perceived should the value of CSR be overleveraged with external 
stakeholders. The development of a framework to present the linkages and interconnections between these ideas are able to generate greater understanding of the relationship.

The research concludes with practical implications for organisational management to recognise the influence and power to benefit its employees, and ultimately the wider entity, through the implementation of CSR. For a business strategy whose primary implications are concerned with the influence on external stakeholders, this study provides deeper understanding of the unexplored relationship between CSR policies and its influence over an individual employees sense of belonging.

Key words: Corporate Social Responsibility (CSR); sense of belonging, employees, Stakeholder Theory; financial industry 


\section{ACKNOWLEDGEMENTS}

Firstly, I would like to thank my family. You have been my constant supporters and encouragers. To my dad, Asoka, thank you for all the discussions (and arguments) regarding my ideas and theories. To my mum, Rangika, thank you for everything you do for me so that I've never had to worry about anything (and also all the numerous times you picked me from the library late at night!) To my brother, Rakitha, thank you for always making me laugh and keeping me calm, no matter how stressed I have been or how much I've taken that out on you! I couldn't have done this without the love and support from you all.

To my best friend and everything else, Sajeem. Thank you for believing in me from the start and never giving up on me throughout it all. You were there with me the entire way and I can't imagine going through this journey, or achieving any of it, without you.

To all the rest of my family and friends, who have heard me go on and on about my thesis, thank you from the bottom of my heart for everything you have done. For the encouragement you have always given me, I have truly been blessed to have such incredible people in my life.

To my beautiful friend, Jaini. Thank you for hours you spent proofreading my work. I know it wouldn't have been easy but I am so thankful for you and all the support you gave me throughout.

To Victoria University of Wellington, what I will take away from my time here is unmeasurable and priceless. I will be forever grateful to all the help and support that I received from the University and all my lecturers and everything I have learnt from you. I would especially like to thank Dr. Todd Bridgman for his guidance. Your words of encouragement and advice will always be appreciated. I would also like to thank Ms. Megan Key for the constant support you provided to all us students throughout our study. There is a reason why we call you the 'Master's Mum' - thank you for always being on hand to sort out any problems or issues that we've had and making sure everything runs as smoothly as possible! 
To all the incredible people who went on this journey with me; Satya, Julie, Tom, Todd, Dylan, Emma and Ruth. I feel so lucky to have had the chance to meet such amazing people. Thank you for all the laughs and memories that kept me sane throughout it all! To my supervisor AProf Urs Daellenbach. I do not even have the words to thank you for all the help you have given me throughout this entire process. Your support, help, advice and encouragement is what allowed me to get to where I am now. I can't imagine having completed this thesis without your guidance and I will be forever grateful for everything you have done.

Finally, to God. This has been one of the most rewarding yet challenging experiences and it wouldn't have been possible without the support and guidance I get from him every day.

"With men this is impossible; but with God all things are possible." Matthew 19:26 


\section{Contents}

Abstract ii

Acknowledgement iv

1. Introduction 1

1.1 Background of Corporate Social Responsibility ................................................... 1

1.2 Corporate Social Responsibility Today ...................................................................... 3

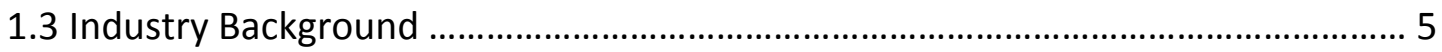

1.4 Statement of Issue

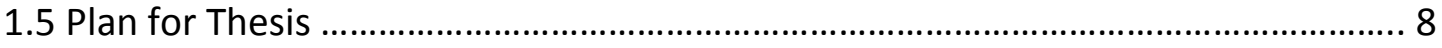

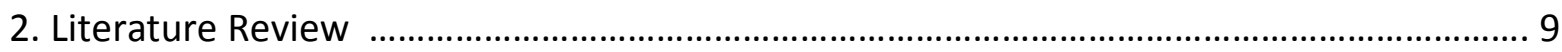

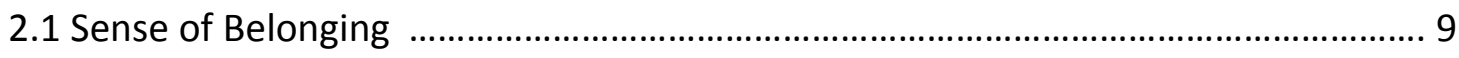

2.1.1 Definitions of a Sense of Belonging ............................................................ 9

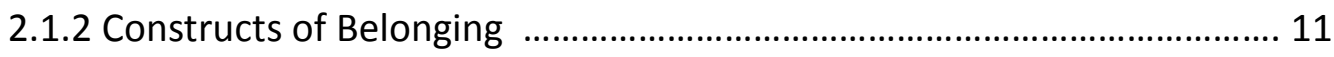

2.2 Belonging within the Organisation ........................................................................ 12

2.2.1 Organisational Identification .................................................................. 13

2.2.2 Employee Engagement ....................................................................... 14

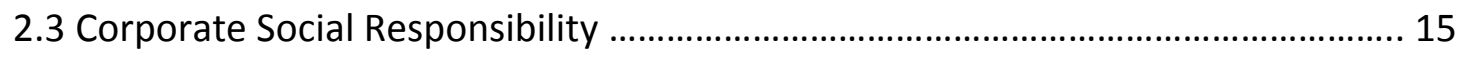

2.3.1 Definition of Corporate Social Responsibility ......................................... 15

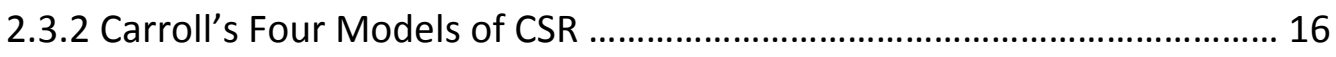

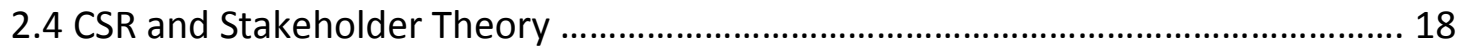

2.4.1 Stakeholder Classification ....................................................................... 20

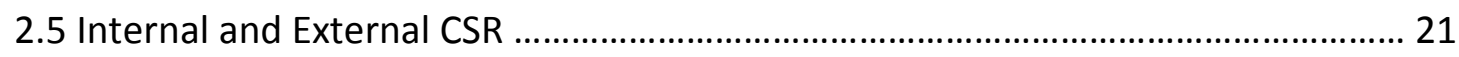

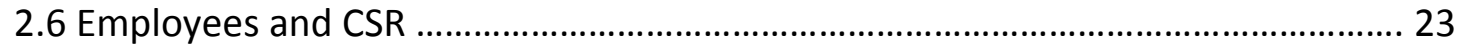

2.6.1 Employee Perception of CSR ................................................................ 24

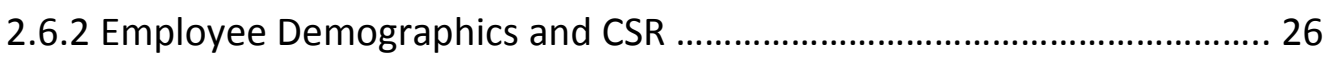

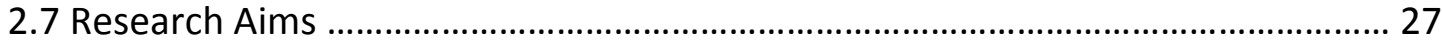

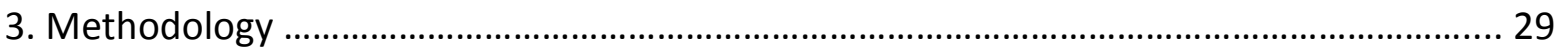

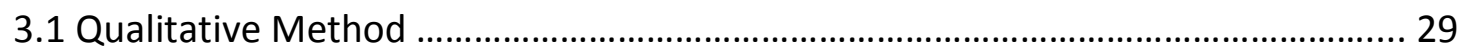

3.1.1 Limitations of the Quantitative Method ................................................. 30 
3.2 Limitations of the Qualitative Method ................................................................. 31

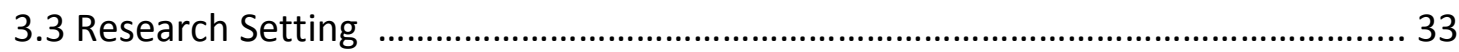

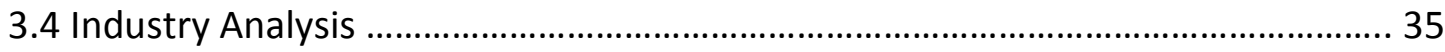

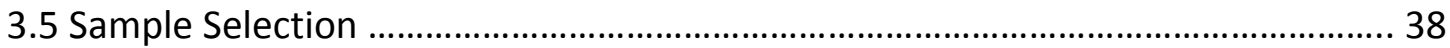

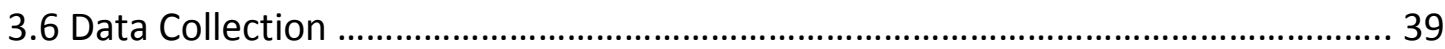

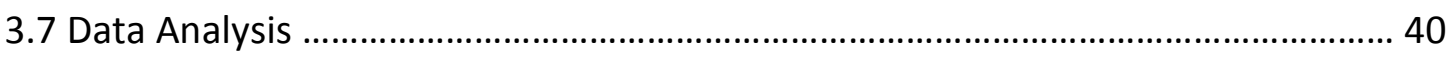

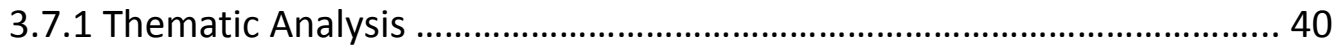

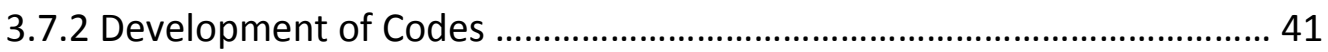

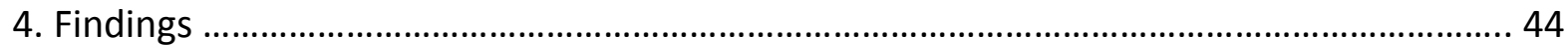

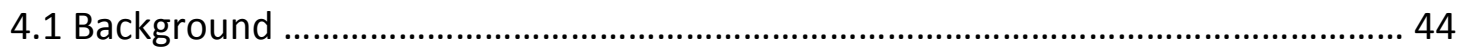

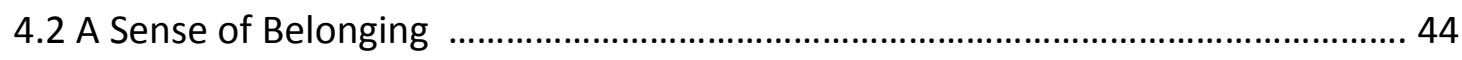

4.3 Understanding Corporate Social Responsibility .................................................... 47

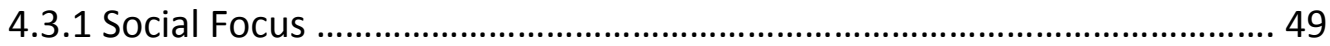

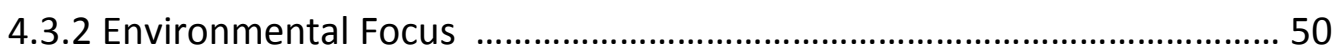

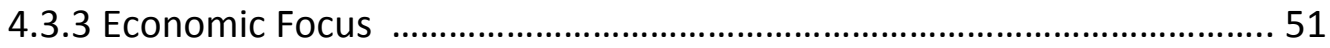

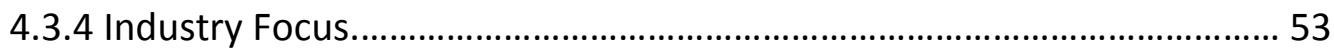

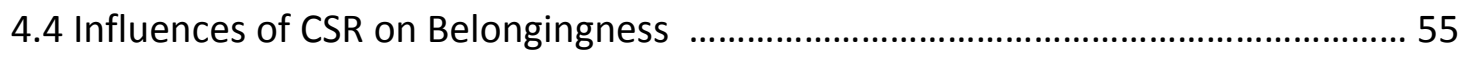

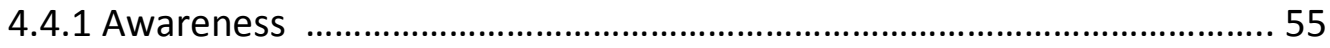

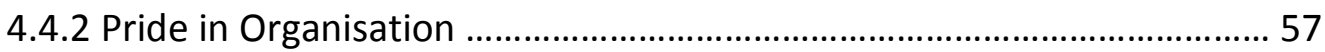

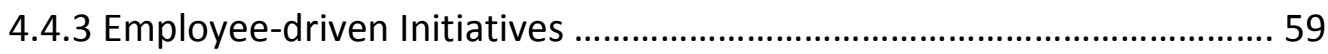

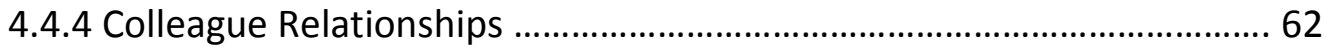

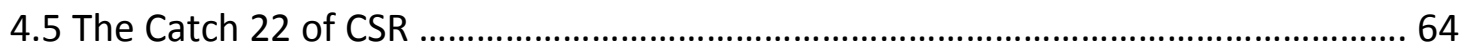

4.6 Other Potential Influences of CSR on Belongingness ........................................... 66

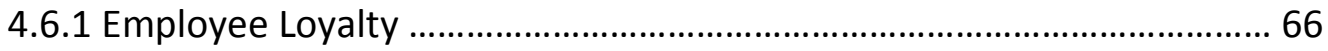

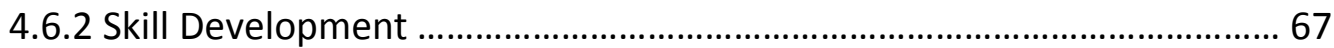

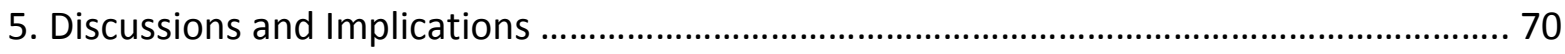

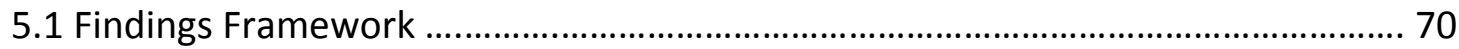

5.2 Loop One: Recurring Emergent Themes …................................................................ 72

5.3 Loop Two: Other Significant Themes …………….................................................... 76

5.4 Loop Three: Overleveraging Value of CSR ............................................................ 78

5.5 Limitations and Implications for Future Research ................................................... 79 


\section{Illustrations}

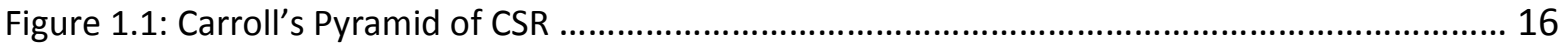

Table 3.1: Profit Distribution by Foreign Affiliates in New Zealand ................................................. 36

Table 4.1: Demographic Factors of Employees Interviewed ........................................................... 44

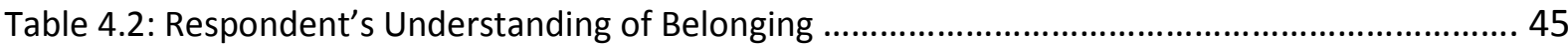

Table 4.3: Respondent's Perception and Understanding of CSR ......................................................... 48

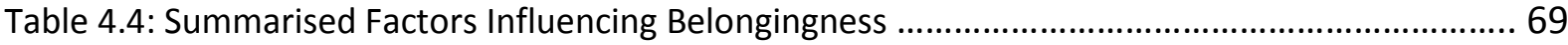

Figure 5.1: Emergent Themes of CSR Influence on a Sense of Belonging ....................................... 71 


\section{INTRODUCTION}

The motivation behind this particular area of research was largely driven by a personal interest in the area of Corporate Social Responsibility (CSR). As a continuingly evolving and developing area, it is being integrated into a wide range of business operations across industries (Werther \& Chandler, 2005). However the comparative lack of an employee perspective has begun to be recognised within the literature (Rodrigo \& Arenas, 2008). That a view of the subject had tended to be missing in the CSR literature, sparked an individual interest into understanding the nature of any underlying relationship between CSR and employees; a significant stakeholder of every organisation.

Furthermore, having gained experience working within the financial sector of New Zealand (NZ), narrowing down the broad concept of CSR to the context of the financial industry was driven by a personal inquisitive interest of the area. In an industry that plays a crucial role in the success and stability of a country's economy, it is inevitable that this sector is primarily associated with financial figures and dollar signs (Treasury, 2007); (Mathieson, 1980). However, with the constant progression of CSR, it added to my personal desire to further examine how non-financial aspects of an organisation were being managed within this sector.

\subsection{Background of Corporate Social Responsibility}

CSR as a concept has steadily increased in its significance and priority. Over time, as the concept evolved and was further developed, its relevance in the global marketplace became more prevalent and recognised (Scherer \& Palazzo, 2009). CSR, whilst still being a relatively new construct, has had a long and varied history that extends as far back as the 1950's (Carroll, 1999). This period of time was identified by Carroll's 1999 study as the emergence of the modern era in CSR, although roots of the concept can be traced back to earlier decades, dating as far back as the 1930's. Since then, the idea became further developed and revolutionised both the literature and practical settings of the organisational context (Carroll, 1999). 
The rapid rise of CSR, particularly throughout the 1970's, is largely attributed to the increase in public awareness and understanding of social and environmental responsibilities that led to increased management concern with corporate image (Clark, 2000). Friedman's notion that a corporation's sole responsibility was maintaining its profitability in order to please shareholders was accepted throughout business dealings, yet is increasingly being discredited as a result of this rise of CSR (Hackston \& Milne, 1996). However, Friedman was only opposed to the idea in that such activities may provide no favourable return to the company, which was seen as the only justification for implementing the concept (Friedman, 1970). As such, Friedman was not against the idea, providing it resulted in benefits returning back to the organisation. This idea was increasingly recognised by organisations and management as the available literature expounded and grew. Subsequently, the potential benefits that could flow back to the corporation as a result of adopting socially responsible practices were becoming more prevalent (Bashir, Hassan, \& Cheema, 2012).

Despite this development, a universal definition of the concept has continually evaded the CSR literature resulting in the emergence of numerous descriptions of the subject (Ciprian-Dumitru, 2013). However for the purposes of this study, Carroll's widely encompassing description was adopted. This particular definition states that "the social responsibility of business encompasses the economic, legal, ethical and discretionary expectations that society has of organisations at a given point in time" (Carroll, 1979; Fu, Haobin \& Law, 2014). For a concept that has been labelled as being both diverging and overlapping (Bauman \& Skitha, 2012), Carroll's broad description has allowed it to be widely inclusive of the different elements that make up the subject. Such an element important to the concept is that of the various stakeholder groups involved in a company. Consequently, as the topic developed over time, CSR has increasingly incorporated aspects of stakeholder theory (McWilliams \& Siegel, 2001). As a result, the existing literature has predominantly focused on the accountability of corporations to the wide range of stakeholders that have a vested interest in the company's success. Here, the concept of CSR extends beyond simply financial accountability to shareholders. This is reflected in the literature with the focus on numerous financial and non-financial obligations owed to various groups that not only have a stake in the business, but also the power to influence its success (De Roeck, Marique, Stinglhamber, \& Swaen, 2014). 


\subsection{Corporate Social Responsibility Today}

Today, CSR continues to evolve and expand, most evidently seen through the public's expectation for companies to adhere to CSR standards and a sustainable business model (Australian Centre for Corporate Social Responsibility, 2014). Further exemplifying such developments within the New Zealand (NZ) context has been the forming of the Sustainable Business Council in January 2012. This influential body was the result of the amalgamation between the existing New Zealand Business Council for Sustainable Development and BusinessNZ's Sustainable Business Forum (World Business Council for Business Development, 2015). The merger established a more powerful and influential voice to govern the sustainable development of NZ businesses. The development of such an organisation is illustrative of the advancements that CSR is making globally and the subsequent rising need for an influential body to provide leadership, guidance and assistance to the NZ business community. The council itself has recognised CSR's position as a central issue in mainstream business operations and as such, its contribution to the success of an organisation is becoming more accepted (World Business Council for Business Development, 2015).

In addition, the growth of the concept is similarly exhibited in many other ways. KPMG's 2013 report of Corporate Responsibility Reporting provides an illustration of current global trends and guidelines in regards to CSR reporting. Furthermore, it presents findings that support and reiterate the increasing imperative of CSR amongst organisations today (KPMG, 2013).

Useful contextual details include;

- CSR reporting in the Asia-Pacific has increased by $22 \%$, with approximately $71 \%$ of companies publishing CSR reports and CSR reporting coming to be considered a mainstream business activity.

- Within the 250 largest companies globally, the CSR reporting rate is stable at $93 \%$.

- $51 \%$ of companies worldwide now include CSR reporting within their annual financial reports, which has risen from 20\% in 2011.

- The percentage of companies deciding to have their CSR reports assured by a major accountancy firm has increased to 67\% in 2013.

- Of the reporting companies, $77 \%$ identify key stakeholders within the CSR reports. 
CSR literature has identified the increasingly positive implications of adopting the concept into business strategies such as enhanced reputations, improving brand and company image as well as boosting morale and increasing the value of their stock (Porter \& Kramer, 2006). While such advantages have been used as justifications for CSR (Bashir et al., 2012), the statistics above are an indication of its increased presence on a practical level. Companies are proactively undertaking initiatives that demonstrate CSR as part of their day-to-day operations and business strategies (Prieto-Carron, Lund-Thomsen, Chan, Muro, \& Bhushan, 2006). Organisations across all industries are commissioning hands on approaches to implementing CSR throughout their business practices in the attempt to ultimately benefit both their local and global communities (Porter \& Kraner, 2006).

With this increase in companies actively getting involved in CSR, stories of organisations going above and beyond their financial responsibilities are becoming more common. As such, they play a crucial role in how they are perceived by their customers, employees and the general public (McWilliams \& Siegel, 2001). A recent example is that of Canadian low-cost airline, WestJet who performed their 'Christmas Miracle for 2014' where the company brought a 'Canadian Christmas' to a town in the Dominican Republic, fulfilling the Christmas wishes of its residents (Mutzabaugh, 2014). The manner in which this effort went viral illustrates the transparency that social media and technology have facilitated for such activities, or conversely the lack of them. Furthermore, it indicates why members of the general public are increasingly aware of and influenced by the social responsibility that companies undertake. The particular activity carried out by WestJet reveals the significance and power of CSR and the potential it has to not only accomplish something positive in the community, but simultaneously create a favourable image of the company. As stated by WestJet's executive vice president, sales marketing and guest experience, Bob Cummings, this initiative is "...an opportunity for WestJetters to enrich lives through our fun and caring culture" (Fong, 2014).

Similar initiatives are increasingly being conducted by companies internationally that are recognising the power of undertaking CSR to communicate to its stakeholders (Morsing, 2006). A concept that was once ridiculed in its earlier history is fast becoming the latest tool in achieving success in the market place, whilst performing a morally accepted function in the community (Jacinto \& Carvalho, 2009). This increase in companies addressing social and environmental needs as part of their strategy and operations have 
added to the momentum of CSR growth and contributed to the numerous new organisations that are adopting such initiatives. With these activities being more publicised and disclosed, the expectation that companies perform a social function is now becoming more universal.

\subsection{Industry Background}

The financial industry, with its dynamic and constantly changing market place has been a crucial element of a nation's economy and as such its success has proved to be crucial. Indicators of performance used to measure this have been primarily financially based with success rates typically assessed via monetary, capital and equity based ratios and figures. Although prior sections have highlighted the increase of CSR reporting by companies, it will be interesting to explore the extent to which non-financial measures of success are taken into consideration by organisations operating in this industry.

While financial institutions are seemingly driven by monetary incentives and motivations, their integration of CSR into business practice is increasingly becoming evident through various initiatives and polices that are being undertaken. An example taken from the banking sector has been the adoption of volunteering programs by multiple institutions throughout NZ. The five most prominent banks in NZ; ASB, ANZ, KiwiBank, BNZ and Westpac have all implemented employee volunteer programmes through which their staff are encouraged to actively participate in activities or help raise funds throughout the local community. In doing so, these organisations are enabling CSR to be conducted through the hands of their own people. In addition to facilitating CSR, these institutions have now created initiatives that have come to be expected by employees, both current and prospective, as well as members of the public. ASB inspires employees to raise funds for charities with the bank matching the amount raised dollar for dollar (ASB, 2014). ANZ, KiwiBank, BNZ and Westpac all offer employees a minimum of one day allocated purely for volunteer work to be completed in the community. BNZ's Closed for Good initiative is one activity that has received significant attention in society and in the media for their organisation wide commitment to enhancing their local communities (BNZ, 2015). While this particular activity has generated arguably more attention, other banking institutions have similar policies that provide their employees with the opportunity to make a difference in their community. KiwiBank offers employees a day off each year to 
volunteer in any area of the community that they please (Kiwibank, 2015). Similarly ANZ has approximated 15,000 hours of community work that is provided by their staff per annum and likewise, Westpac has estimated their staff volunteer time is the equivalent of 15 years full time work for good causes (Westpac NZ, 2015; ANZ, 2015).

In the same way, insurance companies operating within NZ have also incorporated CSR and are increasingly being identified by the sponsorships they are associated with. For example, a leading NZ insurance company, State Insurance has been acknowledged by the public for their commitment to improving water safety, thus benefiting the entire country. Similarly, other prominent insurers such as NZI has been recognised for its commitment to sustainable business practices through their sponsorship of the Sustainable Business Network, and AMI for its sponsorship of grassroots sport. This idea of sport sponsorship is a common and highly publicised area of CSR for many institutions within the financial industry. The top five banks; ASB, ANZ, Kiwibank, BNZ and Westpac are recognised for the sponsorship partnerships they hold with sporting organisations ranging from NZ Football, ANZ Netball Championship, Super Rugby and even individual sporting stars such as Westpac's sponsorship of Sophie Pascoe. The increasing adoption of such sponsorships by the leading companies in this sector enables these institutions to establish their presence throughout the local community and influence how they are perceived by the public.

\subsection{Statement of Issue}

However, while stakeholder relations and engagement have been emphasised throughout the literature, specific groups have received comparatively greater attention. As such, both practical and academic insights into CSR in an organisational context have been primarily centred on these groups (Rodrigo \& Arenas, 2008; Gond, El-Akremi, Igalens \& Swaen, 2010; Zhu, Yin, Liu \& Lai, 2014). As a result, one crucially important group that plays a significant role in the success of any organisation has been overlooked and not reached its optimum level in regards to CSR (Ciprian-Dumitru, 2013). While scholars, academics and managers have allocated resources to discover and understand CSR in relation to customers, environmental groups and the general public, significantly less attention has been attributed to the employees of an organisation. The research conducted by Ciprian-Dumitru has identified this as being largely due to the very 
commonly accepted idea of CSR being primarily related to external activities, thus automatically diminishing the importance of the internal stakeholder group of employees.

This gap is slowly being addressed with recent studies beginning to attempt to understand the effects of CSR on employees, yet the little existing research is primarily focused on attracting a quality workforce, which once again is very much externally focused (Gond et al., 2010). However, this study extends further in an attempt to understand the relationship between the practice of CSR and an existing employee's sense of belonging within the organisation.

This comparative lack of research concerning an employee perspective has been considered to be unusually surprising, given the recognition employees have received both academically and practically (Rodrigo \& Arenas, 2008). Whereas staff had been traditionally regarded as simply there to carry through the production line, their position as a valuable asset within a company has been reflected in the literature that explores the benefits of maintaining a happy workforce (Zhu et al., 2014). Subsequently, the subject of an employee's belongingness within his or her organisation has been discussed in many forms (KPMG, 2013). Yet a large majority of literature pertaining to the idea of belongingness is often discussed or explored in terms of an individuals need to belong. Subsequently, the terms 'need to belong' and a 'sense of belonging', were often used interchangeably despite the distinct differences between the two. While a need to belong depicts an individual's desire to form social relationships, a sense of belonging itself reflects the fulfilled sense of inclusion and the latter is often overshadowed by the focus on the former (Lambert et al., 2013). This research is focused predominantly on this idea of a sense of belonging within an individual employee.

Although it cannot be said that the subject of belonging is undermined, there is a lack of research to suggest a relationship may exist between a sense of belonging and the practice of CSR. A need has been recognised for the further investigation of employees' psychological responses and attitudes towards CSR policies (De Roeck \& Delobbe, 2012; De Roeck et al., 2014). Similarly, while CSR literature has undoubtedly flooded the realm of business and management, the comparatively underwhelming amount of research regarding employees has left a crucial aspect of the subject relatively neglected. The overlooking, and arguably the undermining, of an employee perspective regarding CSR 
has left the already subjective concept incomplete (Eweje \& Bentley, 2006). This research attempts to fill this void in the literature by examining the nature and extent of the relationship between both these relatively unexplored subjects.

\subsection{Plan for the Thesis}

The thesis will be presented as follows;

Chapter Two provides a review and discussion of the existing literature in regards to the areas of belongingness and CSR. Furthermore, it will identify the gaps that exist in the current literature and, in accordance, outline the research aims of this study.

Chapter Three describes the particular research methods undertaken and justifies the choices made in regards to the data collection of the study as well as the intended process of analysis.

Chapter Four discloses and describes the results from the study, drawing on direct quotes from interviewees to present the findings gathered.

Chapter Five discusses the results of the research and draws conclusions from the findings. In particular, with reference to the gaps in literature as well as the limitations and implications of the research, this chapter draws conclusions and presents the contribution to knowledge this study provides. 


\section{LITERATURE REVIEW}

This research is focused on the increasingly adopted construct of CSR within organisations but specifically on the nature and extent to which it may influence an employee's sense of belonging in the workplace. The study is concerned with better understanding how CSR can influence a sense of belonging as opposed to identifying and measuring a specific correlation.

This chapter seeks to review and examine the existing literature that is relevant to understanding the constructs of CSR and a sense of belonging, as well as what is known about their interrelationship. Such a review will provide the basis on which to build from and discover the extent to which CSR has the ability to influence a sense of belonging. Additionally, in doing so, it will also identify the areas that the literature has tended to overlook. As such, this chapter will not only provide greater understanding, but also present the intentions and aims of the study.

\subsection{Sense of Belonging}

\subsubsection{Definitions of a Sense of Belonging}

Humans have been proven to have a strong desire to internalise a sense of belonging in regards to the various contexts, roles and positions which they may hold (Cockshaw, Shochet, \& Obst, 2013). The areas of research that have extensively studied this concept have been largely derived from Maslow's Hierarchy of Human Needs (Hagerty, LynchSauer, Patusky, Maria Bouwsema, \& Collier, 1992). This widely recognised framework categorises belongingness as a basic human need that arises in a variety of contexts in which people are placed (Hornsey \& Jetten, 2004). While the origins of belongingness remain in the field of psychology, the concept has developed and extended into various associated, yet distinct, disciplines, including that of an organisational and workplace context (Cockshaw et al., 2013)

The term 'belonging' encompasses a wide array of definitions and perspectives that include, but are not limited to; self-esteem, identity, acceptance and recognition (Hagerty et al., 1992; Ferris, Brown \& Heller, 2009). However, in defining a sense of 
belonging, the term is often incorrectly used interchangeably with the need to belong, which is typically embodied in an individual's intrinsic motivation for social inclusion and acceptance (De Cremer \& Blader, 2006). The prominence of the need to belong as a primary human need arose through its inclusion within Maslow's hierarchy of human needs which has traditionally, and still continues, to be employed in understanding human behaviour in multiple contexts (Benson \& Dundis, 2003). The need to belong identifies a basic element of human nature that drives someone to create and maintain positive relationships, however it does not necessarily guarantee that a sense of belonging is attained (Lambert, Stillman, Hicks, Kamble, Baumeister, \& Fincham, 2013). A sense of belonging is founded on the ideas of acceptance and recognition and therefore, merely forming relationships do not guarantee that the individual feels accepted and included within the social group (Hagerty et al., 1992; Lambert et al., 2013). A person who has established a sense of belonging has instilled in themselves a greater sense of security, reducing the feelings of anxiety and uncertainty (Anant, 1967). However, this security is only achieved through the acceptance and social support of the group to which the individual belongs. Therefore, while the need to belong may drive individuals to form relationships, it is possible that despite this a person remains excluded, thereby skirting a sense of belongingness. As such, a higher need to belong does not systematically result in an equally high sense of belongingness (Anant, 1967).

This view of an individual's sense of belongingness was defined by Anant (1967) as the "personal involvement in a social system to the extent that the person feels himself to be an indispensable and integral part of the system" (Hagerty et al., 1992, p. 173). As further research concerning this concept developed, this definition, or elements of it, have been used repeatedly throughout the literature to describe a sense of belonging in a wide range of contexts (De Cremer \& Blader, 2006; Lambert et al., 2013). This emphasis placed on the idea of indispensability and being integral is particularly important in an organisational context where employees are seeking to feel capable, significant and worthy at work (Ferris et al., 2009). The majority of these studies have used the terms 'belonging' and 'belongingness' to constitute the same meaning and as such, this study will similarly use the terms interchangeably.

Building further on Anant's description, belongingness has also been defined as creating relationships that evoke a sense of inclusion and membership and subsequently develop 
an individual's sense of belonging (Lambert et al., 2013). Lambert et al's study elaborates further to incorporate the concept of group membership, with the personal and close relationships symbolically representing inclusion within some form of a larger entity. Group membership has been reiterated as a solid basis for a sense of belonging (Van Prooijen, Wilke, \& Van de Bos, 2004). In this regard, group belongingness has been described as a deeply personal and contextually mediated response of an individual as a result of the degree they feel secure, accepted, valued, included and respected by the group (Levett-Jones \& Lathlean, 2009). As such, the ideas of meaningful relationships and group membership have proven to be interrelated and intertwined (Van Prooijen et al., 2004). Inclusion by peers and a sense of "fitting in" thus proves to be beneficial to an individual's sense of belonging within a group or society.

\subsubsection{Constructs of Belonging}

Research into belongingness by Lee and Robbins presented two distinct constructs or measures of the concept based largely upon the self-psychology theory of Kohut (Lee \& Robbins, 1995). These two separate scales; Social Connectedness and Social Assurance, facilitate a greater understanding of the theoretical components that make up an individual's sense of belonging. The distinction between these two constructs, while tapping into independent components of belonging, are seen to provide greater understanding of the overall concept of belonging (Lee \& Robbins, 1995). Lee and Robbins' study argued that the use of these two constructs has the potential to provide a better understanding of the complexity of the dynamics that underlie an individual's sense of belonging.

Social Connectedness is primarily concerned with the individual's opinion of themselves in relation to other people and the social world (Lee \& Robbins, 1998). The focus placed on the emotional connectedness, or conversely, the distance between one's self and other people, in terms of both friends and the general society, relates to the "intense and pervasive sense of security" as referred to by Kohut (Lee $\&$ Robbins, 1995, p. 239). The relevance of dependence on emotional connectedness has previously been alluded to in a prior study that identified two distinct dimensions of belonging (Hagerty et al., 1992). This study identified the first dimension as value involvement which is primarily associated with the experience of feeling valued, needed and accepted. Social 
connectedness is aligned to this dimension that concerns the desire to be valued and accepted by others that surround them (Hagerty et al., 1992). Both these ideas examine components of belongingness that are dependent upon and/or influenced by the ideas, opinions and thoughts of those around them (Lee \& Robbins, 1998). There is an increasing recognition that social ties and integration can influence a sense of belonging. As such, social connectedness and valued involvement provides a way to examine the role these opinions of external members of society can have on an individual's selfperceived sense of belonging (Hagerty \& Patusky, 1995).

In comparison, Social Assurance is concerned with one's reliance upon others, that is, the need to gain a sense of assurance from other external sources (Lee \& Robbins, 1995). Lee and Robbins placed the focus here predominantly on the idea of reassurance and the role it holds in contributing to an individual's sense of belonging, despite the range of sources and situations from which it may arise. This type of social appraisal has been identified as a manner in which individuals can verify their belonging using their external surroundings (Lee, Keough, \& Sexton, 2002). Furthermore, social assurance determines the extent to which an individual's use of talent and skill is dependent upon the external reassurance of those around them (Lee \& Robbins, 1995). This second construct is equally supported by the second dimension from Hagerty et al's study of belongingness that has been identified simply as 'fit'. Built around the premise of identity, this relates to an individual's perception that their characteristics are aligned with, or complement, their system or external environment (Hagerty et al., 1992). Social assurance and the concept of fit provide a link to understanding the external contributions to building an individual's sense of belongingness within their environment. Both these related streams of belongingness reinforce the ability of an individual's identity to be constructed and influenced by the need for congruence with external factors (Cockshaw et al., 2013).

\subsection{Belonging within the Organisation}

Belongingness has previously been identified as context-specific by researchers on the basis that self-esteem is considered a proxy measure of belongingness (Cockshaw et al., 2013). Studies have discovered evidence pertaining to the variation of self-esteem in relation to contextual factors and as such, indicated the possibility of context and environment to influence an individual's sense of belonging (Ferris et al., 2009). A 
particular context increasingly becoming predominant in both psychological and organisational literature is the concept of workplace belongingness. Research has recognised the workplace's significance in a person's self-esteem, happiness and satisfaction of primary needs (Rego, Cunha, \& Souto, 2009).

Organisations are progressively recognising the importance of belongingness and the powerful influence it holds over an employee's cognitive processes, emotional patterns, health and well-being, as well as behavioural responses (Levett-Jones \& Lathlean, 2009). Prior research has corroborated the idea that humans have a desire to internalise a sense of belonging, both in a range of their personal roles as well as other alternate contexts (Cockshaw et al., 2013). As such, an employee's need to fulfil a sense of belonging within the context of an organisation where they embody a role is rising in importance for both the individual and the corporation (Levett-Jones \& Lathlean, 2009). As stated by Gavin and Mason, "a person cannot be genuinely happy if he or she is unhappy at work" (2004, p.381). Therefore, promoting and enhancing an employee's well-being provides corporations with a valuable form of intrinsic motivation that will ultimately increase productivity and employee performance (Rego et al., 2009; Alam \& Rizvi, 2012).

\subsubsection{Organisational Identification}

Organisational Identification (OI) commonly refers to the concept of social identification in a business setting (De Roeck \& Delobbe, 2012). In accordance with Social Identification Theory (SIT), social identification refers to an individual's desire to identify themselves with groups that in turn, enables them to view their identity in a distinct and positive manner (Fu, Haobin, \& Law, 2014). Fu et al's study identified the ability of such a process to reinforce self-esteem and self-concept thus enhancing an individual's sense of belonging.

Ol is a particular form of social identification in which an individual experiences a sense of oneness or belongingness to their organisation (Fu et al., 2014). More explicitly OI is considered to be the extent to which an internal member characterises themselves with the same values and beliefs they attribute to the organisation (De Roeck \& Delobbe, 2012). Consequently, the more an individual identifies themselves with the entity, the more they perceive a sense of oneness with the organisation that therefore enhances the sense of belonging (Fu et al., 2014). De Roeck and Delobbe elaborated further to state 
that OI gives credence to the influence of relationships in developing an individual's attitude and sense of belonging. The formation of relationships with the social group in reference, which in this case, refers to the organisation and its members, translates to the degree to which a member feels accepted by their workplace (De Roeck \& Delobbe, 2012). Consequently, this sense of inclusion is likely to result in an individual increasingly identifying with the organisation. Furthermore these relationships, likely to facilitate group membership, contributes to the maintenance and improving of an individual's health and well being (Lambert, et al., 2013).

\subsubsection{Employee Engagement}

Throughout organisational literature, a general consensus on the definition of employee engagement is lacking with the concept being described differently within different contexts (Ghafoor, Masood, Khan, \& Hijazi, 2011). However, when considered in relation to individual psychological needs, employee involvement through organisational operations has been recognised to develop and expand their sense of belonging (Benson \& Dundis, 2003). Thus the performance of particular tasks and activities carried out by an individual employee is largely dependent upon their sense of association and identification with its employer (Ghafoor et al., 2011). Ghafoor et al elaborated further on employee engagement, noting its ability to decrease the individual's intentions of leaving the organisation on account of the bond that is formed between the corporation and the employer. The resulting sense of belonging that is established therefore has the potential to moderate the strength and the length of membership to the organisation (Gond et al., 2010).

In addition to the bond created with the organisation, employee engagement can fulfil an individual's psychological needs by facilitating desire for inclusion and acceptance by social groups. Encouraging employee engagement or participation within an organisation provides opportunities for individual employees to create meaningful relationships with a social group, in this case the organisation, and thus satisfy a basic need for belonging and inclusion (Levett-Jones \& Lathlean, 2009). Employee engagement increases the identification of an individual with its employer while simultaneously reaffirming their desire to be respected and valued amongst their social group (Van Prooijen et al., 2004). This interaction and involvement with their organisation has been identified as a crucial 
component of attaining a sense of belonging (Ghafoor et al., 2011). Characterised as a developmental process, achieving this sense of belonging is reliant upon such interactions between the individual and his or her external environment (Lee \& Robbins, 1995). Furthermore, corporations stand to benefit from advocating such employee engagement practices as Maslow stated, an employee's optimal level of functioning is dependent on organisational practices taking into consideration human nature and their needs and motivations (Levett-Jones \& Lathlean, 2009).

Overall, a sense of belonging has been extensively examined throughout the literature. Although, a predominant focus has been on the "need to belong" it's distinction from a sense of belonging has been addressed as a crucial component of understanding the concept. In doing so, the potential benefits of achieving a sense of belonging have emerged throughout research. Extending to an organisational context, the benefits of instilling a sense of belonging in an employee has been shown to provide benefits through the advantages of $\mathrm{Ol}$ and employee engagement. As such, the importance of the concept to organisations is paramount and has come to be recognised throughout the literature.

\subsection{Corporate Social Responsibility}

\subsubsection{Definition of Corporate Social Responsibility}

The lack of a universally accepted definition of CSR and the various methods used to examine it have led to its identification as a dynamic concept throughout the literature. The complexity of creating a collective definition was summed up by Votaw who stated that CSR "means something, but not always the same thing, to everybody" (Votaw, 1972, p. 25). Throughout the years, the emerging concept of CSR proved to be a topic of interest, provoking debate amongst scholars and contributing to the conceptualisation of this relatively new idea (Carroll, 1999). As such, the development of this concept was built upon the constant reviews and updates that were made to the idea by various academics (Gond et al., 2010).

While the lack of a single definition has led to the creation of numerous descriptions, Carroll was able to provide a more encompassing definition of the idea, which is still commonly being used today (Fu et al., 2014). Described as, "the social responsibility of 
business encompasses the economic, legal, ethical and discretionary expectations that society has of organisations at a given point in time" (Carroll, 1979, p. 500), Carroll thus established the four dimensions of the concept, an element which has been integrated in the numerous definitions that have since been developed (Schwartz \& Carroll, 2003; Visser, 2005; Fu et al., 2014). Consequently this widely inclusive definition has been adopted for the purposes of this study.

\subsubsection{Carroll's Four Models of CSR}

Carroll's identification of the four levels that make up CSR have encompassed the wide range of obligations and responsibilities that an organisation has to an equally large range of stakeholders (Carroll, 1979). As a result, succeeding developments in the continuing attempts to define and conceptualise the subject of CSR have been founded on this distinction of the four levels (Fu et al., 2014). While each dimension has been distinguished, Carroll's 1979 study specified that the four levels were not intended to be considered as mutually exclusive and as such, it is possible for a single corporate action to embody all or multiple dimensions. Carroll's development of the pyramid of CSR provided a tool through which to gage greater understanding of the dimensions included within CSR (Aupperle, Carroll, \& Hatfield, 1985; Jones, Bowd, \& Tench, 2009).

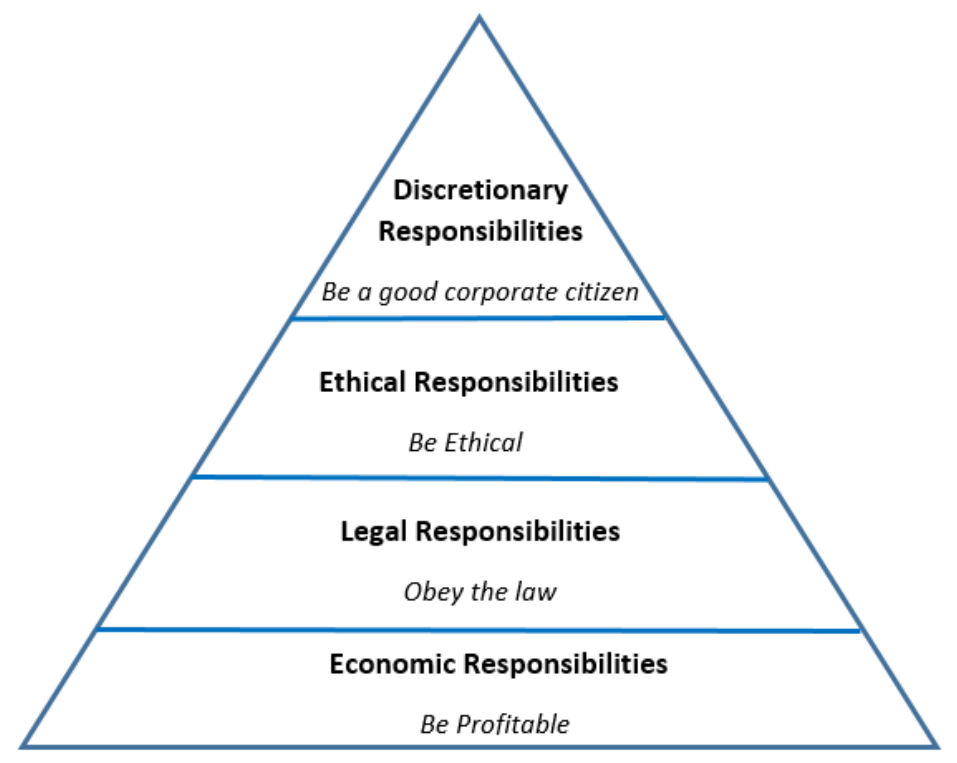

Figure 1 Carroll's Pyramid of CSR (Carroll, 1991); (Ciprian-Dumitru, 2013) 
Economic responsibilities represents the basic foundation upon which corporates are established (Ciprian-Dumitru, 2013). Whilst Carroll's model acknowledges the multiple obligations that an organisation must uphold, economic responsibility infers its primary role, in that a business institution "is the basic economic unit in our society" (Carroll, 1979, p. 500). Moving further up the pyramid presents society's role in sanctioning the laws and regulations to which an organisation must comply in its business operations (Carroll, 1979). These legal responsibilities have historically been considered to coincide with economic obligations and as such, indicates the standards of fairness that is expected and required in the carrying out of business operations (Carroll, 1991; Schwartz \& Carroll, 2003). The ethical responsibilities that are expected of organisations, extend beyond those "ground rules" that are codified into law, yet are still assumed to be adhered to by society (Carroll, 1991; Ciprian-Dumitru, 2013). Moral philosophy acts as a guiding principle to these ethical obligations imposed upon an organisation (Joyner \& Payne, 2002). With economics becoming increasingly intertwined with the concept of morals, the expectations of society is largely founded on underlying moral codes such as justice, rights and fairness (Carroll, 1991; Strautmanis, 2008). The expectation of businesses to abide by such ethical responsibilities have become ingrained as a component of CSR, yet it must be noted that such responsibilities are susceptible to changes due to changes in circumstances and what society considers to be acceptable (Carroll, 1991; Ciprian-Dumitru, 2013). Changes of societal views and values in turn is reflected in the onus of responsibility placed on corporations (Carroll, 1991; CiprianDumitru, 2013).

The last stage of Carroll's pyramid of CSR, discretionary responsibilities are, as inferred by the name itself, responsibilities and actions undertaken at the discretion of the organisation (Carroll, 1979). Also termed, philanthropic responsibilities, these actions of the company are in response to the expectation to be a "good corporate citizen" (Carroll, 1991, p. 42). While society has increased its desire for companies to fulfil discretionary responsibilities, a company's decision to engage in such activities is voluntary and is not required by ethical or moral standards (Halme \& Laurila, 2009). Such philanthropic responsibility is often realised through the provision of a company's resources, both financial and non-financial, which enhance the organisation's aura of a good corporate citizen (Carroll \& Shabana, 2010). However, this commitment is not defined by moral 
codes but rather, is driven by the corporations own "desire to engage in social roles" (Carroll, 1979, p. 500; Carroll, 1991). Yet, society is increasingly coming to expect such commitment from companies, driven by the public who are more closely observing the operations of the business (Gray, Kouhy, \& Lavers, 1995).

This rise of discretionary activities is an indication of the departure from solely economic dominated obligations (Jamali, 2006). Consequently the broader responsibilities of the corporate have come to be widely addressed through the Triple Bottom Line. Encompassing economic, social and environmental obligations of a company, the concept attributes the success of a company to all areas of responsibility as opposed to purely financial (Norman \& MacDonald, 2004). The emergence of these three areas of responsibility have been identified as precursors to achieving sustainability (Jamali, 2006). While these three categories have come to be commonly accepted by most, they can, and have been, attributed different degrees of importance by various stakeholder groups. However, as Jamali identified, this concept must be looked at holistically in order to satisfy the various responsibilities as well as the numerous stakeholders.

\subsection{CSR and Stakeholder Theory}

Traditional views of business identified shareholders as the sole stakeholder to whom a business owed any responsibility (Hackston \& Milne, 1996). Historically, a business was created exclusively as an economic entity operating primarily on a profit incentive (Carroll, 1991). This idea of running a business was asserted through the endorsement by the world's arguably most influential economist, Milton Friedman (The Economist, 2006). His view was captured in his response to social responsibility, saying; "there is one and only one social responsibility of business - to use its resources and engage in activities designed to increase its profits so long as it stays within the rules of the game..." (Friedman, 2002, p. 63). This profit driven view of business emphasises shareholders to be the exclusive concern for corporations. Such an exclusively economic perspective of business implies that a company fulfils its social responsibility through the generation of profits, which in turn provides the returns that shareholders or investors are seeking (Bauman \& Skitha, 2012) 
However this doctrine of business and management is increasingly becoming obsolete with the rise in awareness and significance of CSR (Hackston \& Milne, 1996). The rise of CSR has highlighted its underlying foundation that is largely based on the numerous stakeholders to whom an organisation as an obligation (Clarkson, 1995). Consequently stakeholder theory has come to be recognised and accepted as a dominant paradigm in CSR (McWilliams \& Siegel, 2001). As defined by Barnett via a stakeholder-centric perspective, CSR initiatives are "discretionary allocation of corporate resources towards improving social welfare that serves as a means of enhancing relationships with key stakeholders" (De Roeck \& Delobbe, 2012, p. 398).

CSR is repeatedly defined in a similar manner, observing the role of an organisation's multiple stakeholders, as identified by Aguinis to be "context-specific organisational actions and policies that take into account stakeholders' expectations and the triple bottom line of economic, social and environmental performance" (Aguinis, 2011, p. 855; Bauman \& Skitha, 2012, p. 65). The component of stakeholders within these definitions addresses the crossover of stakeholder theory into CSR literature (Morsing, 2006). The success and the mere existence of any organisation is attributed to the integration of these stakeholder's expectations into business strategy and operations (Dawkins \& Lewis, 2003; De Roeck \& Delobbe, 2012; De Roeck et al., 2014).

Moving past the traditional narrow focus on shareholders, managers have increasingly come to recognise the importance of expanding their breadth of interested groups, i.e. stakeholders, to whom they are held accountable (Logsdon \& Lewellyn, 2000). Their obligations to this wider audience epitomises the idea of "social responsibility" as CSR takes into account the needs and concerns of all groups and parties that "contribute to the firm's wealth creation process" (Sachs, Maurer, Ruhli, \& Hoffmann, 2006, p. 506). Subsequently, managers have continually been faced with various demands from the numerous stakeholder groups for the allocation of resources towards CSR initiatives, often specified at meeting the distinct needs of each group (McWilliams \& Siegel, 2001). Yet despite these differences among stakeholder groups, their general understanding of CSR is primarily concerned with the corporations "recognition of broad responsibilities" (Dawkins \& Lewis, 2003, p. 188). As a result the perception of an organisation's CSR by the multiple stakeholders is important and what is being expected of these companies is becoming increasingly demanded (Lee, Kim, Lee, \& Li, 2012). 
As expectations of companies by stakeholder groups increase, so too does the power of its influence in the marketplace (Dawkins \& Lewis, 2003). Stakeholders are increasingly expecting organisations to willingly undertake responsibilities that illustrate company values and morals are consistent with their own (De Roeck et al., 2014). As such, the extent to which such obligations define the stakeholder's perception of the company's character and morals is significantly rising in importance (Morsing, 2006). CSR has progressively come to be thought of as a "key stakeholder relationship-building activity" (De Roeck et al., p. 92), proven to provide "indications of the positive impacts of businesses on their stakeholders" (Turker, 2009, p. 411). As initially identified by Carroll, "there is a natural fit between the idea of CSR and an organisation's stakeholders" (Carroll, 1991; Turker, 2009).

\subsubsection{Stakeholder Classification}

Throughout the extensive literature on stakeholders, researchers have categorised these interested groups into various classes in an attempt to clarify the concept (Turker, 2009). Most commonly used is the relatively straightforward distinction between that of primary and secondary stakeholders which is done so on the basis of their influence upon the strategy, operations and long-term future of the organisation (Clarkson, 1995; De Roeck et al., 2014). Groups classified under the "primary" category are those thought to be of critical importance to the survival and future of an organisation which typically includes customers, employees, shareholders and suppliers (De Roeck et al., 2014). Without the contributions of these stakeholders, an organisation's ability to operate as a going concern is considerably diminished, with the dissatisfaction of any of these groups resulting in severe damage to the organisation. Such devastating effects have been illustrated through the numerous organisations that have failed to successfully manage stakeholder relations and have ultimately led to its collapse.

Contrastingly, secondary stakeholder groups are characterised by their ability to inflict significant damage, despite a lack of direct engagement in transactions with the organisation (De Roeck et al., 2014). More specifically, they have been defined as "those who influence or affect, or are influenced by or affected by, the corporation, but they are not engaged in transactions with the corporation and are not essential for its survival" (Clarkson, 1995, p. 107). Therefore, this group of stakeholders typically consist of NGOs, 
local communities, the natural environment and the media (De Roeck et al., 2014). These stakeholders maintain the ability to sway public opinion and perception in regards to the performance of the organisation. As stated by Freeman "some groups may have as an objective simply to interfere with the smooth operations of our business" (Clarkson, 1995, p. 107).

While there are numerous additional ways in which stakeholders have been categorised, the basic primary and secondary distinctions allows greater understanding on the different needs and interests of diverse stakeholders (De Roeck et al., 2014). Although there are other measures through which to divide and distinguish between stakeholder groups, the majority of these are able to be classified under the umbrella terms of primary and secondary. As such, the proper management and balance of these often conflicting expectations help contribute to the success of any corporation (Clarkson, 1995). Identifying this stakeholder distinction is crucial as it facilitates the understanding of the relationship each group has with the organisation (Russo \& Perrini, 2009).

\subsection{Internal and External CSR}

Similar to the categorisation of stakeholder groups, the concept of CSR has been separated into distinct areas. Although it has been recognised as lacking a fundamental, universally accepted definition, scholars have been able to divide the broad areas, allowing deeper insight into the nature and underlying tendencies of the concept (De Roeck et al., 2014). Despite previous attempts to define the concept through the development of various models and frameworks such as Carroll's theory, comparatively less research has been directed towards the idea of internal and external CSR (Skudiene \& Auruskeviciene, 2012). Skudiene and Auruskeviciene's study also identified the role of stakeholder theory as a basis on which CSR can be specifically classified. As such, the various components and practices that make up CSR has been aligned with the specific stakeholders and can be classified as either internal or external on the basis of which parties it seeks to satisfy (Kim, Lee, Lee, \& Kim, 2010).

Internal CSR has been characterised as including employees' welfare and business ethics (Kim et al., 2010). This description has been further supported by a 2013 study that specified internal CSR to be initiatives of an organisation that pertains to employee's 
physical and psychological well-being (De Roeck et al., 2014). With employees being the largest and most prominent internal stakeholder group, Skudiene and Auruskeviciene identified that the majority of internal CSR practices are centred on health and safety, training, work-life balance and the well-being of staff. In addition, an organisation's respect and understanding for basic human rights, including and not limited to, diversity and equal opportunities fit the description and can be classified as internal initiatives (Kim et al., 2010). At the most basic level, external CSR is distinguished from internal CSR on the basis that it is focused on the image and reputation of the organisation as opposed to its internal dealings and operations (Skudiene \& Auruskeviciene, 2012). Therefore, as indicated by the name, external CSR are those initiatives employed by an organisation, directed towards satisfying its wide reaching external stakeholders (De Roeck et al., 2014). Emphasis on the range of external stakeholders has led to external CSR repeatedly being associated with corporate philanthropy and community contributions. This is therefore reflective of the manner in which the organisation interacts with its physical environment and ethical stance to its external stakeholders (Brammer, Millington, \& Rayton, 2007).

Despite this distinction in the literature, research has emerged that attempts to uncover the relationship between employees and external CSR (Peterson, 2004). Studies such as Brammer, Millington, and Rayton's and Peterson's research conducted in 2004 have indicated the ability of a favourable reputation to boost staff morale and thus enhance the organisational commitment of individual employees. Consequently, these employees are able to attain a sense of pride through their association with a company accredited with a positive and favourable image (Peterson, 2004; Brammer et al., 2007). Peterson in particular, discusses the potential of external CSR to create a sense of attachment as a result of the ethical stances and initiatives undertaken by the organisation. Such a view is particularly important in the light of studies arguing internal CSR activities aimed at employees are often underdeveloped the expense of an organisations preoccupation with its external policies to please external stakeholders (Ciprian-Dumitru, 2013). However these studies promoting the correlation between external CSR and employees lack the ability to explain the underlying reasoning behind these relationships (De Roeck et al., 2014). 


\subsection{Employees and CSR}

Prior sections have discussed the emergence, development and subsequent rise of CSR within the organisational context. Despite its lack of definition, the fundamental understanding of the concept has been based on the idea of addressing the extensive range of stakeholders of an organisation (De Roeck \& Delobbe, 2012). This core element of the concept is the reason why employees have been recognised as an important stakeholder to the company (Gond et al., 2010). The staff of an organisation hold a unique power in the sense that they are key to successfully conveying the brand of the organisation to the wider public (Harris, 2007). The current literature has slowly begun to recognise the significance of an employee's motivation and loyalty in establishing a competitive advantage through the implementation of CSR (Rodrigo \& Arenas, 2008). Furthermore, in the context of CSR, the burden of ensuring ethical practice in the day-today context is sufficiently implemented and carried out, rests with the employees of the organisation as opposed to its governing board (Collier \& Esteban, 2007). Despite this, employees have surprisingly received minimal attention in the literature and remains relatively unexplored in the realm of CSR (Rodrigo \& Arenas, 2008). Similar to CiprianDumitru's criticism of internal CSR activities, the focus on employees is comparatively undermined with the emphasis of CSR predominantly centred on external stakeholders (Ciprian-Dumitru, 2013).

The gradual introduction of an employee viewpoint into the literature has been evident in recent years, yet the majority of such research has emphasised the attraction of a quality workforce as opposed to focusing on existing employees (Chong, 2009). As a result, the emphasis has been on the impact of increased corporate attractiveness for the purposes of gaining prospective employees (Gond et al., 2010). Discussing further, Gond et al identified the idea of corporate attractiveness as an important component of corporate reputation and thus, a marketing tool which companies have employed to appeal to prospective employees. The incorporation of CSR into business strategy and operations creates the impression of a responsible organisation and consequently enhances their company reputation whilst simultaneously attracting a higher quality and qualified workforce (Strand, Levine, \& Montgomery, 1981; Albinger \& Freeman, 2000). The exploration of this positive signalling effect that CSR can have on valuable future 
employees is largely externally focused and driven. Yet the internal influences of CSR on existing employees and the retention and satisfaction of staff tend to be overlooked both in an academic and practical sense (Gond et al., 2010).

Emerging research is beginning to address this gap in the literature yet still requires substantial work in order to develop understanding of the relationships between CSR and the influence upon employees. The need for this aspect to be further acknowledged and understood grows with the power and influence that CSR continues to accumulate. As it becomes increasingly accepted as a form of differentiation, both researchers and management will need to recognise the role employees play in successfully attaining a competitive edge via CSR (Rodrigo \& Arenas, 2008).

\subsubsection{Employee Perception of CSR}

The lack of a general consensus regarding its definition illustrates the subjective nature of CSR as a concept itself. Further elaborated upon by Skudiene and Auruskeviciene who stated the ability of CSR to mean different things to different people at different times, presented the difficulty in determining a universally accepted definition (Skudiene \& Auruskeviciene, 2012). As such, it is evident that individual perception has played a significant role in how CSR is viewed and understood. This has similarly been reflected in discovering the effects on employees of a company (Aguilera, Rupp, Williams, \& Ganapathi, 2007). The 2010 research study conducted by Gond et al recognises the significance of perception in that, the extent to which employees are influenced by CSR is reliant upon their individual perceptions of the practices conducted (Gond et al., 2010). Therefore, an employee's perception of an organisation's CSR was identified as a crucial factor in determining the extent to which they can be influenced by it. The study by Gond et al presented three antecedents that has the potential to shape an individual's perception of CSR initiatives and activities:

\section{Awareness of CSR}

First and foremost, the researchers acknowledge that the extent to which an individual perceives CSR is dependent on their awareness of the actions of the company. Previous studies stressed the importance of communicating CSR initiatives and in doing so, addressed the ability of employee awareness to create a more favourable association for individuals with the organisation (Chong, 2009). Awareness can thus be determined as a 
fundamental building block in creating a favourable perception in the minds of an employee. "After all, employees can't be proud of something they aren't aware of" (Stawiski, Deal, Gentry, \& Rweyongoza, 2011, p. 6).

2. Personal Beliefs of CSR

The study uncovered that an individual employee's personal and political attitudes are translated to the manner in which they perceive and evaluate the importance of particular CSR initiatives, an idea that has been reiterated in other studies (Rupp, Skarlicki, \& Shao, 2013); (Farooq, Farooq, \& Jasimuddin, 2014). This is closely aligned to the theory that the variations in an individual's self-concept, that is, personal values, often leads to differing relationships between CSR and individual commitment (Brammer, 2007).

3. Congruence of Organisation and Employee Values

This fit between personal and organisational values and attributes has the ability to increase the attractiveness of an organisation and thus create a favourable perception of the organisation's CSR policies. The identification of any individual with its employing organisation is likely to strengthen and grow if the company is promoting similar values which the employee holds in high regard personally (Chong, 2009).

These antecedents provide a useful backdrop against which to attempt to measure employee perception and fosters greater understanding of the effects of CSR on this stakeholder group. However, CSR perceptions cannot be stated as static constructs and as such, these antecedents are not an exclusive guideline as to how employee perceptions can be understood (Rupp, Skarlicki, \& Shao, 2013). An employee's perception of CSR has numerous implications for their subsequent behaviour and this has been recognised in the emerging literature that addresses its influence over employees (Kim et al., 2010). The manner in which the employee views the corporate image of its employing organisation has the ability to influence job satisfaction positively while simultaneously reducing turnover (Riordan, Gatewood, Bill, \& J, 1997). In addition, the work attitudes of an employee has been recognised to be determined by the perceptions they hold of the company (Peterson, 2004). Elaborating further, an employee's understanding of the ethics of their employer contributes to developing a sense of identity with their organisation (Rupp, Ganapathi, Aguilera, \& Williams, 2006; Bashir et al., 2012; Skudiene \& Auruskeviciene, 2012). Consequently their view of the organisation 
has been seen to manipulate the manner in which the company is viewed through the lens of the employee. Furthermore, an employee's willingness to participate and contribute to the organisation is inherently influenced by the perceptions that are created in their minds (Aguilera, Rupp, Williams, \& Ganapathi, 2007).

\subsubsection{Employee Demographics and CSR}

The relationship between an employee and the organisation has been understood in numerous ways. Just as perceptions have the ability to manipulate this relationship, so too do the various demographic factors such as culture, background, etc. that are inevitable with a large group of individuals (Ramasamy \& Yeung, 2009). Findings have suggested that the extent to which CSR can impact on an employee's commitment to the organisation can be largely attributed to the particular employees in question and this is where the importance of demographic factors is emphasised (Stawiski et al., 2011).

Studies have historically highlighted that the values held by individuals can be influenced by gender differences and consequently can create variations in the manner in which CSR is perceived and evaluated (Brammer et al., 2007; Strautmanis, 2008). Brammer et al's study identifies men as having a stronger preference for economic concerns as opposed to women who have a greater concern for the discretionary behaviour of a corporate. This distinction has been further elaborated upon and explained to have risen as a result of female discrimination within an organisational context (Peterson, 2004). Peterson determined that inequality displayed within the work place can be attributed to being an underlying reason as to why women place greater value on ethical treatment throughout a corporation. This reasoning was evidenced and justified by women's greater preference to adhere to rule and regulations with the belief of preventing further discrimination within the workplace (Peterson, 2004).

Just as gender differences translate to differences in perception of CSR, so too does generational differences. With a rising new generation that believes "social responsibility is a business imperative" (Martin, 2005, p. 39), it is evident that the generational differences of employees contribute to varying perceptions of CSR. A significant feature that has come to define this generation has been the importance of personal values that more often than not, outweighs pay as a determining factor for joining or continuing on with a particular employer (Berry, 2014). Berry's study illustrates the significance of the 
alignment of values for employees of this generation who are more inclined to turn away from a job whose values are not congruent with their own. In addition, there is evidence to illustrate that the primary concern of Gen $Y$ has shifted away from those of prior generations and now lies with community CSR and its subsequent effects regarding brand image and reputation (Wu \& Wang, 2014). Such findings illustrate the significant effects generational differences in the way of thinking can affect the perception of both external and internal CSR for employees.

The perspective of CSR has also been seen to be influenced by the organisational level of an individual employee. The study undertaken by Stawiski et al identified this particular demographic factor as a crucial contributor to how CSR is perceived throughout the organisation. Individuals that hold a higher position within a corporation is more likely to perceive its CSR activities favourably as opposed to those at lower levels (Stawiski et al., 2010). Stawiski et al attributed this largely to the sense of ownership typically present among higher level employees as it is their choices and decisions that establish the particular initiatives implemented throughout the organisation. Such thinking by individuals holding senior positions also often leads to the overlooking of lower level staff as their comparative lack of knowledge regarding CSR is often forgotten by management, thereby leading to lower levels of commitment by workers further down the hierarchy (Stawiski et al., 2011). This therefore further justifies the significance of the communication of CSR, particularly for lower level employees.

\subsection{Research Aims}

A breadth of literature has covered the concept of CSR however, this study will address the relatively limited attention attributed to its influence upon employees of the organisation. Although it has been recognised that an employee centric perspective has become introduced throughout the literature, this idea is predominantly associated with recruiting potential future employees. Furthermore, there is a lack of research assigned to understanding the relationship CSR may have in fostering a sense of belonging amongst current employees. 
In acknowledgement of this gap in the existing literature, this research has the aim of seeking to accumulate knowledge, and ultimately generate a better understanding of the relationship between an organisation's CSR practices and its subsequent impacts upon an employees sense of belonging. In doing so, its primary focus is gaining an understanding of how the perception and individual understanding of these policies influence their sense of belonging.

In doing so, the research will address the following questions:

1. What is the nature and extent of the relationship between CSR and an employee's sense of belonging?

a. Do employees perceive CSR as having a significant influence over their sense of belonging within the workplace?

b. Are there commonly recurring effects of CSR upon an employee's sense of belonging that allow for greater understanding of the relationship? 


\section{METHODOLOGY}

"The meanings that we give to events and things come from their qualities. To understand our lives, we need qualitative research." (Berg \& Lune, 2012, p. 3).

\subsection{Qualitative Method}

The method chosen for this research is built on its objective to address the gap in the literature regarding the nature of the relationship between belongingness and CSR. While both of these areas are each relatively deeply explored by researchers, the combination, and any interrelationship of the two has been comparatively absent. As a result this research is primarily focused on understanding the relationship between the CSR of an organisation and the individual employee's sense of belonging within the workplace. Accordingly, research could have followed the path of testing each concept individually with the aim of finding a quantitative correlation between the two. However, this study is primary concerned with understanding the underlying mechanism of how one might influence the other, insight that would have likely been lost had a quantitative approach been undertaken. Therefore, in order to sufficiently satisfy the aims of the study, a qualitative research method that values the search for a more holistic meaning was adopted as the appropriate choice (O'Leary, 2004).

In seeking to understand how CSR affects an employee's sense of belonging, emphasis was placed on individual perceptions which plays a key role in the generation of findings and understanding. The limited existing research have identified that the extent to which an employee is affected by CSR is reliant on the degree to which that activity is congruent with their personal values (Bauman \& Skitha, 2012). As such, there is an overriding need to engage with individual respondents to draw out informative personal responses that will explain the extent to which their sense of belonging was impacted on by CSR. Such a form of data collection is therefore crucial to meeting the objectives of the study. This is facilitated through a qualitative method which has been specifically characterised as acquiring data on the perceptions of respondents from the inside (Miles, Huberman, \& Saldana, 2014). Understanding these perspectives will ultimately create greater understanding of the respondents themselves and how each are influenced by CSR 
(Fossey, Harvey, McDermott, \& Davidson, 2002). In this study, both CSR and belongingness in themselves are concepts subject to individual opinions and this therefore needs to be reflected in the method through which the data is collected (Rupp et al., 2006; Levett-Jones \& Lathlean, 2009). In order to understand how individuals thought about, understood and reacted to these concepts in their work life, their lived experiences and personal ideologies need to be taken wholly into consideration. Therefore a qualitative approach is chosen first and foremost to allow participants to expand on the meanings they have attributed to these concepts in order to better understand their relationship.

\subsubsection{Limitations of the Quantitative Method}

To further understand the reasoning behind a qualitative approach, it is also useful to understand why a more traditional quantitative method will prove to be ineffective. The basic and most common distinction from qualitative research is that "the notion of quality is essential to the nature of things" (Berg \& Lune, 2012, p. 3). Certain experiences cannot be defined or understood effectively through numbers and require a method of understanding the meaning that underlies them. The extent to which CSR influences an employee's sense of belonging cannot be quantified or accurately generalised to the population. The previously mentioned findings by Bauman and Skitha's study emphasises the role of perception and indicates that what stirs a positive influence in one individual may not necessarily have the same effect upon another (Bauman \& Skitha, 2012). Consequently, attempting to generalise findings rather than recognising and valuing each distinct response can cause insightful data pertaining to how CSR influences an individual sense of belonging to be lost. Whereas qualitative methods recognise and value the variations in individual responses, quantitative methods seek objectivity and rigour (O'Leary, 2004). It is this rigor in results that enables objective, numerical data to be gathered, typically through questionnaires or surveys (Carr, 1994). Such a study minimises the bias of subjectivity in its study as the researcher and participant are treated as two separate and distinct entities (Sale, Lohfeld, \& Brazil, 2002). However these forms of data collection are limited solely to what is asked of respondents with little ability to stimulate further discussion or ask for clarification. Consequently as stated by O'Leary, there are often constraints to engaging with participants and encouraging more honesty and depth in the information gathered (O'Leary, 2004). For the purposes 
of this study, the lack of interaction with participants will fail to provide the same insight and understanding that can be achieved through a qualitative approach.

These features of the quantitative approach are ultimately not particularly relevant to the objectives of this specific study. "Qualities are like smoke; they are real and we can see them, but they won't stand still for us or form straight lines for our rulers to capture" (Berg \& Lune, 2012, p. 4). Similarly, the specific manner in which CSR policies and a sense of belonging are perceived by an individual pose significant difficulty in creating an accurate and reliable scale to allow for quantifiable measurement. Rather, a qualitative approach that recognises the subjectivity that is inevitable and facilitates the study of an individual's perception provides a more appropriate method to comprehend this relationship (Marshall \& Rossman, 2006).

\subsection{Limitations of the Qualitative Method}

Despite the benefits that are evident through the use of a qualitative method, there are limitations that must recognised. A common argument against the use of qualitative research is the consequent lack of objectivity in the study (Sandelowski, 1986). The possibility of distorted findings has fuelled criticism towards the close relationship between researcher and subject (Carr, 1994). Carr's study elaborated further, stating that connecting with those being studied on a deeper personal level can allow the researcher's personal views to become intertwined with participants, thus creating subjectivity of findings. However in this study, the insight and elaborations gathered from each individual would not have been possible through a quantified means of study.

While a qualitative approach meant that the research built rapport and established a relationship with each individual participant, steps are purposefully decided on to avoid researcher bias from entering the conversation. Specific attention will be paid to ensure questions do not direct participants to certain answers but rather maintain open lines of communication where respondents may expand and elaborate on their own personal opinions. Furthermore, participants will be made aware of the general overview of the research however, the nature and extent of the specific relationship under study will not be revealed. This was decided to avoid respondents being led to answer according to what they believe the study is after. Ultimately, the implementation of a qualitative method will allow perspectives, insights and rich individual knowledge to be derived, all 
contributing to a fuller understanding of the nature of the relationship between CSR and belongingness.

A defining characteristic of this form of research has been the typically smaller sample sizes as a way to ensure quality of data over quantity (O'Leary, 2004). Unlike quantitative methods which can predetermine the minimum sample size necessary through computations and analyses, qualitative sampling is more relative to what is hoped to be achieved through the study (Sandelowski, 1995). Smaller sample sizes in a qualitative approach has often been criticised as being significantly below the generally accepted standard in quantitative methods in order to satisfy generalisability. However, this study is more concerned with quality and richness of the data which is better fulfilled through the use of a qualitative method. Whereas quantitative methods seek to control variables to the greatest extent possible, qualitative methods recognise and address these variables as crucial elements to the study, a component that is key to this particular research. Therefore, while the sample size may be significantly smaller, a qualitative method has the ability to recognise uncontrollable social variables that defy the constraints of quantitative methods (Holliday, 2007). This study does not attempt to control variables such as individual's backgrounds, interests, values and beliefs to the same extent that a quantitative study would. Rather, this method embraces them by allowing participants to venture into these aspects with the aim of uncovering new knowledge. Furthermore, as previously mentioned, this study is conducted with the aims of developing an understanding of the mechanism of how CSR can influence an individual's sense of belonging, which is reflective of the research questions established. As such, it is important to note that it is not undertaken as a study to test theory but rather to develop theory. Therefore, whereas a larger sample is needed to generate and test for the existence of correlations, this is not the intention of this study. Rather, the smaller sample will provide more meaningful data that develops the theory and understanding that underlie how the concept of CSR can influence a sense of belonging.

\subsection{Research Setting}

In designing this study, the research was chosen to be conducted within a single organisation operating in the NZ financial industry, specifically in the country's capital, Wellington. While concentrating the study within one organisation may limit the range of 
responses from participants, it will allow a variety of CSR initiatives to be analysed through the various perceptions of employees from all levels throughout the organisation. By focusing on the one organisation, there is the ability to discover how the same policies and procedures can be viewed by different people. Furthermore, there is the potential to comprehend how various demographic factors and personal ideologies can influence the relationship between CSR and a sense of belonging. Such insights will allow greater understanding of an individual's manner of thinking. In line with the objectives of this study, understanding how the same initiatives are perceived by different people will also provide insight into the extent to which certain activities will influence an individual's sense of belonging. There will be an opportunity to compare and contrast the responses of employees in regards to the same range of initiatives, policies and procedures which will allow a more holistic understanding. Therefore looking at the same policies through the different viewpoints of various employees will facilitate greater understanding of the nature of the relationship.

In selecting a single organisation for this study to focus on, there were many factors that had to be taken into consideration in order to ensure a suitable decision was made. The size of the organisation was an important element as there needed to be a variety of employees that ranged in terms of age, background, gender and position to ensure a diverse sample could be selected. Furthermore as a major focus of the study is the influence of CSR, the organisation needed to have demonstrated the presence of such policies throughout its operations. The institution that was ultimately selected was able to satisfy this criteria, being a prominent organisation that accommodated a range of employees at various levels. Initial research into the organisation provided evidence to suggest that CSR was upheld and being carried out in its operations.

Concentrating the study within the boundaries of Wellington, NZ was primarily chosen as a result of the many conveniences it allowed. The thesis was undertaken with a specified timeframe of nine months, a comparatively shorter period in which to complete the research which necessitated data collection be during a short time window of NovemberDecember. As a result, the timeline was considerably reduced, with the need to get Human Ethics Committee (HEC) approval and liaising with the organisation to organise the interview process, also needing to occur within the first 6 months. The process of gaining HEC approval was required prior to data collection and involved outlining the 
objectives and intentions of the research to the committee to ensure ethical boundaries are, and will not be crossed. With the aim of protecting the interests of both participants and researcher, the approval required such information pertaining to, but not limited to, project details, key dates, participant details, informed consent, storage and use of data and relevant documents. The process required the submission of an initial application which then needed to be peer reviewed and finally any necessary amendments were made before final acceptance of the research was granted. Organising permission with the organisation also required a process of communication and negotiation in order to come to an agreement of the terms of participating in the study. Management was clear in its request that confidentiality, of the organisation and its employees were maintained. In addition, interviews were to be carried out on the organisation's premises, with the necessary resources provided by the organisation. Management were given the preferences for the participants, yet the decision on who is involved in the study ultimately lies with them. Therefore, coordinating these various requirements in a short time window meant concentrating the study in the city where the thesis is being conducted will enable easier access to the organisation and their range of employees. The process from arranging, organising, conducting interviews right through to collecting information will be made significantly easier and manageable by limiting the study to Wellington.

However, with the research being limited by the boundaries of NZ, and more specifically Wellington, it has inevitably restricted the ability to collect as diverse a set of responses/participant viewpoints that may have been feasible through a more dispersed sample population. While this may have reduced the representativeness of the findings, NZ's population demographics have enabled this study to have a comparatively more diverse sample regardless of its size.

Further narrowing the research scope to the financial industry of NZ was done as it presents a contrasting context to which CSR is typically researched. CSR by definition is primarily concerned with the non-financial aspects of an organisation that describes its success in terms beyond traditional measures centred on profitability. Selecting an industry that is typically associated with more monetary measures of achievement, can provide an interesting insight into how CSR is perceived in such a context. In relation to this industry, selecting Wellington as the sole region for data collection was also 
complementary. Being the capital of the country and thus a hub for economic and fiscal policy concerns, it was appropriate that the financial institution studied was from this geographic region.

\subsection{Industry Analysis}

While a specific focus on the financial industry was initiated by a personal interest in the area, it also provided the potential to explore CSR in a context typically perceived as preoccupied with economic advancement. As such, a greater exploration of this particular sector is warranted to provide overall greater understanding of the context of the study.

As defined by the New Zealand Treasury, "A country's financial system comprises a myriad of financial instruments and services offered to firms and investors by a range of markets, organisations and individuals" (Treasury, 2007). In NZ, the major components of the financial industry includes the banking sector, the insurance sector, the venture capital/private equity market, the public equity market, the corporate bond market, nonbank financial institutions and the foreign exchange market. However foreign ownership plays a large role in this industry, with the large players in both the banking and insurance sectors primarily owned by overseas parents. 


\begin{tabular}{|c|c|c|c|}
\hline INDUSTRY & NET PROFIT & $\begin{array}{l}\text { DIVIDENDS PAID TO } \\
\text { OVERSEAS INVESTORS }\end{array}$ & $\begin{array}{l}\text { PERCENTAGE OF } \\
\text { PROFITS PAID TO } \\
\text { OVERSEAS INVESTORS }\end{array}$ \\
\hline $\begin{array}{l}\text { AGRICULTURE, FORESTRY AND } \\
\text { FISHING }\end{array}$ & 264 & 32 & $12.1 \%$ \\
\hline MINING & 1,139 & 494 & $43.4 \%$ \\
\hline MANUFACTURING & 1,907 & 1,059 & $55.5 \%$ \\
\hline CONSTRUCTION & 159 & 18 & $11.3 \%$ \\
\hline WHOLESALE TRADE & 1,005 & 373 & $37.1 \%$ \\
\hline RETAIL TRADE & 326 & 91 & $27.9 \%$ \\
\hline $\begin{array}{l}\text { TRANSPORT, POSTAL AND } \\
\text { WAREHOUSINGO }\end{array}$ & 154 & 116 & $75.3 \%$ \\
\hline $\begin{array}{l}\text { ADMINISTRATIVE AND SUPPORT } \\
\text { SERVICES }\end{array}$ & 129 & 9 & $7.0 \%$ \\
\hline $\begin{array}{l}\text { RENTAL, HIRING AND REAL ESTATE } \\
\text { SERVICES }\end{array}$ & 187 & 51 & $27.3 \%$ \\
\hline $\begin{array}{l}\text { HEALTH CARE AND SOCIAL } \\
\text { ASSISTANCE }\end{array}$ & 76 & 4 & $5.3 \%$ \\
\hline $\begin{array}{l}\text { FINANCIAL AND INSURANCE } \\
\text { SERVICES }\end{array}$ & 9,003 & 5,964 & $66.2 \%$ \\
\hline
\end{tabular}

Table 3.1 Profit Distribution by Foreign Affiliates in New Zealand, year ended 31 March 2012

(Statistics New Zealand, 2014, p. 19)

The table above, adapted from Statistics NZ, presents a breakdown of the profit distribution by foreign affiliates and a visual aid to understanding the role of foreign ownership in the financial and insurance services industry. Statistics NZ concluded that of all industries, the financial and insurance services industry were among the most likely to send the majority of their profits offshore.

Within the banking sector, only $6 \%$ of the 25 registered banks are NZ owned institutions in a direct contrast to other OECD countries where research has upheld that foreign owned banks are directly disadvantaged to locally owned counterparts (Dermiguc-Kunt \& Huizinga, 1999; The Reserve Bank of New Zealand, 2014). The banking sector itself is dominated by the five large banks, holding $85 \%$ of all assets held in the banking system, and all of which are foreign owned. While NZ banking grew and strengthened following the global financial crisis, the majority of these profits are sent offshore to international parent companies (3News New Zealand, 2012). The insurance sector too is dominated by a few large players, the majority of whom are Australian owned and thus contributes to the outflow of profits (Reserve Bank of New Zealand, 2004). This immense proportion of its profits that are flowing out of the country has resulted in many disgruntled members of the public (Norman, 2011). In an industry that holds prominent influence within the NZ 
economy, the outflow of profits has increasingly raised questions as to the responsibility such institutions have to its domestic environment, local consumers and members of society.

In addition to the idea of foreign ownership, the financial industry has been heavily influenced as a result of various global campaigns and events. The global financial crisis of $2007 / 2008$ is one of the events whose effects extended internationally and significantly influenced all organisations operating within the NZ financial sector (Crotty, 2009; Claessens, Dell'Ariccia, Igan, \&Laeven, 2010). However the adversities faced by the banking institutions of NZ were comparatively lower that other global counterparts due to limited interconnectedness with international markets. However, this did not prevent the government's need to issue guarantees of bank liabilities to support the funding issue faced by many institutions (Bollard \& Ng, 2014).

With the near collapse of the financial system and the economic models that underlie this, governments chose to contribute significantly to "bail-out" the deteriorating banking and financial system (Langman, 2013). Consequently, the financial system and its elite were effectively saved and have since prospered however, as the rich became richer, average people suffered through loss of jobs, foreclosed homes and evictions (Shuttleworth, 2012). This led to a distrust of the financial system and stimulated the establishment of the Occupy Movement, an international movement that sought to reform the current system in which the wealthiest hold the power and continue to write the rules for the already imbalanced economy (Occupy Together, 2015). The global protest is based on the concept of the "99\%" that refers to the widening gap between the rich and the poor, with the accumulation of wealth among the top $1 \%$ of income earners (Fletcher, 2014). On this premise, the movement has targeted much of its efforts on the financial industry, emphasising the "too big to fail" banks, that have been saved and bailed out at the expense of the taxpayers that make up the 99\% (Occupy Together, 2015). The idea of being "too big to fail" and the understanding that "bankers got away with it" which have been highlighted by Occupy, have continuously eroded the industry's reputation (Jenkins, 2014). 


\subsection{Sample Selection}

The process of selecting a sample was another decision that was heavily influenced by the adoption of a qualitative method. As previously mentioned, the process of selecting a qualitative sample differs from that of a quantitative approach. Whereas quantitative research typically calls for random sampling, qualitative research requires purposeful sampling whereby subjects are chosen on the basis of their ability to provide rich information in regards to the objectives of the study (Coyne, 1997). Being able to choose respondents specifically for purposes of in depth information have been identified to produce more insight and understanding than could be achieved through attempts to generalise (Patton, 2002). In determining the sample for this study, the initial number of participants desired was between 15-20 as this was thought to be an appropriate size to adequately answer the research question (Marshall, 1996). This size was considered to be big enough to gain a range of perspectives yet small enough to ensure valuable, insightful information can be collected.

As well as the desired sample size, certain characteristics of individual participants were decidedly preferred. Demographic factors such as age, gender, background and position in the organisation were thought to contribute to the manner in which an individual might perceive and understand the phenomenon under study (Stawiski et al., 2011). Consequently, varying backgrounds and personal differences among individual respondents was important to understand their effects on how both CSR and belongingness was construed. Furthermore, a range of respondents would enable more diverse and discerning data to be gathered.

Once the desired sample size and characteristics were determined and agreed upon by the organisation, the final selection of the individual participants were passed over to the management of the organisation. During initial meetings with management to arrange and organise the study, the desired features of the sample size were given to the manager who subsequently found willing participants that met the requirements. Originally, 17 respondents were selected however, due to unforeseen events, this number was reduced to 14 when 3 participants were unable to attend the interviews. However, although slightly less than was envisaged, the reduced number of respondents was not expected to significantly diminish the value of the information gathered. 
Fourteen respondents are still considered an adequate sample size to generate understanding and answer the research questions. The sample is still expected to provide a diverse set of respondents that will be able to deliver the information necessary to enable deeper understanding.

\subsection{Data Collection}

The data collection procedure for this study will be conducted as a semi-structured, faceto-face interview with individual participants lasting approximately 45 minutes. Each interview will be conducted in the head office of the organisation in Wellington. This location was requested by management of the organisation, who agreed to provide a private room for the interviews to take place. Doing so is not only easier for respondents but also enables data collection to be conducted within the organisational context which is expected to be insightful for data gathering. Firstly, employees will be more at ease in a familiar setting. More importantly, conducting interviews within the organisational context can open up the possibility of respondents elaborating further as a result of their surroundings. Being within the boundaries of the organisation while being questioned on the company's policies regarding CSR has the potential to trigger certain pieces of information or personal experiences that may contribute to a more overall understanding. Respondents will be assured of their anonymity prior to the start of the interview and an information sheet also provided with details of the research and its objectives. Participants will be given the opportunity to raise any questions or concerns not covered in the information sheet and then asked to sign a consent form before the interview commences.

As the most commonly used method of qualitative research, the social interaction that is an interview fits perfectly with this research that aims to understand the complexities that underlie an individual's perception of the phenomenon under study (Mason, 2003). Therefore, an interview method of data collection was particularly selected in order to explore the subjective variables that would otherwise be overlooked through a survey, questionnaire or other form of quantitative research method.

The semi-structured interview with each individual participant will facilitate a one-onone interaction with employees that can be conducted in a conversational style in order to encourage in depth, insightful responses from participants. This informal manner as 
opposed to a rigorous question and answer arrangement will be implemented with the aim of urging respondents to open up and disclose personal experiences, beliefs and values. This has largely been based on the idea that semi-structured interviews have been identified as means to draw out "authentic accounts of subjective experience" (Miller \& Glassner, 2004, p. 125). As such, adopting an open ended style is done with the aim of enabling participants to enlighten the researcher on their view of CSR and individual sense of belonging. In addition, the conversationalist approach to the interviews can help build rapport between researcher and participant, facilitating a sense of trust and thereby provoking deeper and insightful responses.

The semi-structured nature of the interview means broad themes or areas of discussion will be predetermined but also left vague enough to foster further conversation and discussion. These categories will be limited to the broad concepts of belonging and CSR with participants encouraged to explore and recount their understanding of the relationship between the two in their own words, experiences and beliefs. This was purposefully carried out based on the idea that interviews are largely a mechanism to "generate empirical data about the social world by asking people to talk about their lives" (Holstein \& Gubrium, 2004, p. 140). Allowing employees to talk about their experiences and personal thoughts in relation to the social phenomenon under study provides greater ability to understand and assess the variables at play. A copy of the rough structure of each interview is provided in Appendix 1.

\subsection{Data Analysis}

\subsubsection{Thematic Analysis}

As stated by O'Leary, regardless of the method ultimately chosen, the objective of any form of analysis is to transform the data collected into a meaningful understanding (O'Leary, 2004). For this study, to understand the raw information collected from respondents, a thematic analysis was adopted as it provides "a method for identifying, analysing and reporting patterns (themes) within data" (Braun \& Clarke, 2006, p. 79) and has the ability to describe data in great detail. In line with the objectives of this study, a method through which to identify common or contrasting patterns in the data enables understanding of the relationship to be developed. 
While qualitative research has been stated to boast rich and insightful findings, the process of analysing and understanding the raw data has often proven to be difficult as a result of the complexity of the information gathered (Jacelon \& O'Dell, 2005; Miles et al., 2014). This intricacy of the information gathered has presented a challenge to researchers who need to produce meaning from their data while maintaining that the insight and richness of the data is not lost through the process of analysis (O'Leary, 2004). O'Leary identified thematic analysis as a method to counter this challenge and provide a tool to search for meaning in the often messy data that qualitative research provides. It is for this reason that a thematic analysis was decided on to carry out the analysis of the data in this study.

\subsubsection{Development of Codes}

The nature of the data gathered will result in transcripts that are expected to hold an array of responses requiring systematic analysis to ensure common themes and patterns are identified and understood. Developments in software have enabled qualitative researchers to minimise this physical labour of analysis however, such software was not selected to be undertaken in this study. Due to the relatively smaller sample size, there is no requirement for the additional support of a coding tool but rather, reliance on manual analysis alone.

Manual thematic analysis requires a process of coding, whereby the data is reduced and categorised to various themes that are labelled accordingly (O'Leary, 2004). As a result, themes emerge and simultaneously enable the analysis and interpretation of the data to occur (Miles et al., 2014). In this study, despite the small sample size, it is projected to yield relatively large amounts of rich data that need to be analysed effectively to draw out meaningful understanding and conclusions. In order to code the data and search for emerging patterns and themes, template analysis was selected as a specific style of thematic analysis to establish initial codes (King, 2012). King expounded on the method as a form of identifying codes or a 'template' that represents the themes extracted from the raw data (King, 2004). With the emphasis that was placed on the individual opinion and judgement of the respondents, prescribed and specific analysis is too restrictive whereas template analysis offers the flexibility to adapt to the requirements of the particular research (King, 2004). 
In undertaking this method of analysis for this study, King's 2004 work is used as a fundamental basis to create a template which will then be tailored for the purposes of this research. In developing the preliminary codes the themes emerging from the text, which in my study refers to the transcripts of interviews, will be labelled as a code throughout the analysis. The coding can then be made more detailed through the use of hierarchical coding whereby the relative importance of each code, and subsequently, each theme is made more evident (King, 2004). Therefore developing the template and the process of coding the information in itself aids the analysis of the data (Miles et al., 2014).

Capitalising on the flexibility this technique offers, pre-determined codes will be selected from the theoretical research and then adapted, refined and added to, following consideration of the data gathered. The semi-structured interview schedule was selected as the starting point in developing initial codes prior to the collection of data. The rough outline of the interview schedule is reflective of existing literature explored a priori to data collection and based on the research objectives of the study and therefore provides a useful guide to analysis (Waring \& Wainwright, 2008). This will then be further elaborated upon based on the recurring codes and themes arising from the data collected. The importance of this refinement process has been reiterated as necessary to reveal the inadequacies of the original set of codes (King, 2004). Upon emergence of an area of theme of significance not yet identified amongst the initial codes, additions will be made to include these via the creation of a new code or label. This process will be repeated as each interview transcript is explored in greater detail, ultimately leading to the creation of the final template of codes.

While template analysis has been hailed as a technique to organise and order the seemingly overwhelming amount of data that qualitative research provides, King noted the difficulties arising as a result (Mason, 2003). Through the process of coding, this method identifies ideas that most commonly occur, thus establishing collective patterns and themes throughout the data (Miles et al., 2014). However building on analysis by emphasising these recurring codes has the potential to lose the individual voice of respondents through the over-descriptiveness of the technique (King, 2004). The overgeneralisation of information from individual participants can allow personal experiences and perspectives to be lost among aggregated themes (King, 2004). This limitation was 
particularly significant for this study as it relies heavily on personal beliefs to understand the intricacy of how CSR can influence an individual's sense of belonging. As previously mentioned, what can constitute as important for one employee may not necessarily be the same for another (Bauman \& Skitha, 2012). Consequently, this research accepts that less frequently appearing pieces of information may add valuable insight into the overall understanding. For this reason, the template analysis adopted in this study will be altered to include codes that may not necessarily appear regularly across all transcripts, yet may be deemed to be relevant to the findings. In the end, the flexibility of the approach allowed it to be tailored to meet the specifications for this study. 


\section{FINDINGS}

\subsection{Background}

The patterns themes and understanding presented in this chapter has been derived from a thematic analysis of the transcripts. Quotes extracted from the interviews have been used alongside the findings to reiterate the key ideas that emerged and enhance the understanding of the relationship between CSR and an employee's sense of belonging. The chapter is organised into sections that represent the common themes that were uncovered. These sections also include less regular yet significant pieces of information that contributes to greater understanding. The table below provides a brief compressed background to the participants involved in this study.

\begin{tabular}{l|lllll}
\multicolumn{2}{l}{ RESPONDENTS } & \multicolumn{5}{c}{ DEMOGRAPHIC FACTORS } \\
\hline & Gender & Age Group & Stage of Life & $\begin{array}{l}\text { Time spent at } \\
\text { Organisation }\end{array}$ & $\begin{array}{l}\text { Position/Level within } \\
\text { Organisation }\end{array}$ \\
$\mathbf{1}$ & F & $30-50$ & Middle aged & 6 years & Front facing \\
$\mathbf{2}$ & F & $30-50$ & Working parent & 8 years & Front facing \\
$\mathbf{3}$ & F & $30-50$ & Working parent & 14 years & Manager \\
$\mathbf{4}$ & F & $<30$ & Working parent & 1 year & Front facing \\
$\mathbf{5}$ & M & $30-50$ & Working parent & 10 years & Analyst \\
$\mathbf{6}$ & M & $30-50$ & Working parent & 17 years & Senior Auditor \\
$\mathbf{7}$ & F & $30-50$ & Working parent & 14 years & Manager \\
$\mathbf{8}$ & F & $<30$ & Career focused & 5 years & Senior Associate \\
$\mathbf{9}$ & F & $30-50$ & Career focused & 5 years & Manager \\
$\mathbf{1 0}$ & F & $30-50$ & Middle aged & 19 years & Manager \\
$\mathbf{1 1}$ & F & $<30$ & Recent graduate & $16-17$ months & Analyst \\
$\mathbf{1 2}$ & F & $30-50$ & Working parent & 8 months & Private customers - \\
$\mathbf{1 3}$ & & & & & Front Facing \\
$\mathbf{1 4}$ & F & $30-50$ & Middle aged & 9 years & Senior Analyst
\end{tabular}

Table 4.1 Demographic Factors of Employees Interviewed

\subsection{A Sense of Belonging}

“...if you don't feel like you belong here, there's no point even staying around here. So even if you have to go to a smaller organisation where you feel belongingness and wanted, it makes a big difference in terms of your wanting to come to work on a daily 
As one of the two main phenomena in this study, understanding an individual's sense of belonging was a crucial starting point. It was important to first identify the extent to which this was a central aspect in the life of the employees. All employees interviewed, regardless of their position within the organisation highlighted the importance of having a sense of belonging in the workplace. While the degrees of importance varied among respondents for a range of reasons, a mutual consensus was that the workplace should foster a sense of inclusion between colleagues and was a crucial component of organisational culture. The table below summarises each participant's personal view of the value that a sense of belonging holds through direct quotes extracted from their interview.

\begin{tabular}{|c|c|}
\hline RESPONDENT & EVIDENCE \\
\hline 1 & $\begin{array}{l}\text { "...I've never really known such an inclusive environment so I kinda didn't know what I } \\
\text { was missing. It was only when I came here that I realised..." }\end{array}$ \\
\hline 2 & $\begin{array}{l}\text { "It's not so much about salary, I mean you know that you have to pay your bills, but } \\
\text { it's not about that, it's about how you're valued as a person within the organisation." }\end{array}$ \\
\hline 3 & $\begin{array}{l}\text { "And you know people do want to belong...it always amazes me how many people } \\
\text { want to be involved in different activities that we'll put out there and people do want } \\
\text { to have that sense of belonging." }\end{array}$ \\
\hline 4 & $\begin{array}{l}\text { "...I really enjoy that social aspect which I didn't use to have for a long time so...I feel } \\
\text { like I'm living again, not just looking after my children, I'm having a life again." }\end{array}$ \\
\hline 5 & $\begin{array}{l}\text { "Very important. Because if you don't have that then you can't give your } 100 \% \text { to the } \\
\text { organisation as well." }\end{array}$ \\
\hline 6 & "A sense of belonging, I suppose if I hadn't, I wouldn't have stayed that long." \\
\hline 7 & $\begin{array}{l}\text { "Absolutely yes [have a sense of belonging]. Like I feel quite strongly that I wouldn't } \\
\text { go work for another [financial institution]." }\end{array}$ \\
\hline 8 & $\begin{array}{l}\text { "I could tell that it made a difference about how I would feel about coming into work. } \\
\text { And I guess also it influences your attitudes and your behaviours." }\end{array}$ \\
\hline 9 & $\begin{array}{l}\text { "...I've got to feel like I'm a good fit for the organisation as much as have the skills to } \\
\text { do the job." }\end{array}$ \\
\hline 10 & $\begin{array}{l}\text { "As an employee I think that's very important to me [a sense of belonging]. You know } \\
\text { you spend a lot of your life at work and so you've got to enjoy it." }\end{array}$ \\
\hline 11 & $\begin{array}{l}\text { "...I guess it is important but it's not as important as if I was you know, about to buy a } \\
\text { house and you know get some commitments." }\end{array}$ \\
\hline 12 & $\begin{array}{l}\text { "...you're going to put more into it, invest more into it yourself, the more that you feel } \\
\text { a part of that." }\end{array}$ \\
\hline 13 & $\begin{array}{l}\text { "...because you spend a lot of time at work, you should be able to feel like you can } \\
\text { identify with them and have a sense of belonging that it's a part of who you are and } \\
\text { you're a part of what it is." }\end{array}$ \\
\hline 14 & $\begin{array}{l}\text { "I think it actually helps you enjoy your time more. And it's not the praise ....it is just } \\
\text { you feel a sense of, you're a part of an organisation, you're included..." }\end{array}$ \\
\hline
\end{tabular}


The importance of a sense of belonging is revealed through the bulk of participants identifying a culture of belongingness as a 'deciding factor'. Over half of all respondents explicitly stated that a sense of belonging is either something they would actively seek out if they were to look for another job, or alternately, would not leave the current organisation as a result of the sense of belonging they hold.

"And if you don't have that attachment, you'll always be on the lookout for something else which can offer that kind of encouragement."

\section{- Respondent Five}

However, while comparatively less common, respondents also addressed the developmental nature of a sense of belonging, deeming that it cannot be determined from the outset but rather, is a feeling that grows and strengthens over time with organisations. With the job initially viewed as solely a source of income, respondents noted that workplace belongingness developed over time and as such cannot be judged or selected as an inherent characteristic of an organisation when not an employee.

"...I don't necessarily look for that, I think you're just aligned with it..."

- Respondent Twelve

\section{"...it's more something that's developed in me over that time."}

\section{- Respondent Nine}

It is also key to note the significantly fewer responses that inferred a less favourable view of the concept. Only one respondent, a younger employee and recent graduate, while understanding the importance of having a sense of belonging, noted its lack of relevance to her current situation. With a more short-term view in regards to staying with the organisation, having or achieving a sense of belonging was not as paramount as other goals and aspirations that included the possibility of travel and overseas job opportunities.

"For me, thinking short-term, I'm probably going to be doing an OE [Overseas Experience] so for me personally, it's a 'nice to have' rather than a long term 'I'm going to dedicate my life to [the organisation]"' 
Respondents at a later stage of life identified the differences in priorities and needs from their initial entrance to the work force. Interviewees identified that their primary objective was guaranteeing employment as opposed to fulfilling a sense of belonging. However this desire developed over the term of their employment. As such a sense of belonging within the organisation seemed to be more valued amongst those employees that had been working for a longer period of time.

"I think also that you kind of grow up a little bit as well. It's a pretty different story when you join an organisation...so you grow up and you have a different perspective of life."

\section{- Respondent Three}

\subsection{Understanding Corporate Social Responsibility}

Very similar to the responses gained about a sense of belonging, a positive perception of a company's CSR activities was the prevailing conclusion by employees. There was a mutual acceptance of CSR as reputable business conduct, yet personal beliefs and perspectives contributed to the understanding of what the concept entailed. During the interview, each respondent was given the diagram depicted below that identified the three significant areas of CSR. In doing so, the potentially differing lenses through which CSR could be perceived was introduced to the employees. This was done as a way of gauging how CSR was understood and the extent to which each individual associated themselves with a particular aspect of the concept.

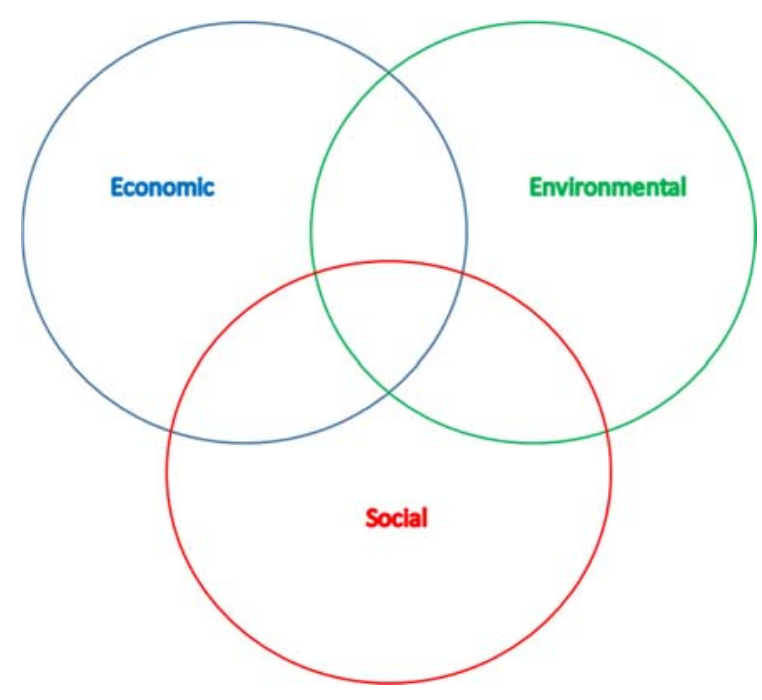


The table below has condensed the views of interviewees with respect to which area they believe CSR is more aligned with. 


\begin{tabular}{|c|c|c|c|}
\hline Respondent & Social & Environmental & Economic \\
\hline 1 & $\begin{array}{l}\text { "It's the community but it's the community within } \\
\text { the building as well." }\end{array}$ & & \\
\hline 2 & & $\begin{array}{l}\text { "Well you know it's [the environment] kind of an } \\
\text { easy one." }\end{array}$ & \\
\hline 3 & $\begin{array}{l}\text { "The contributions to charity and the well-being of } \\
\text { society and the employee volunteer programs that } \\
\text { we do much here and that people really value." }\end{array}$ & $\begin{array}{l}\text { "There is definitely the environmental perspective } \\
\text { and you see that." }\end{array}$ & \\
\hline 4 & & & "There is an economic cost to everything." \\
\hline \multicolumn{4}{|r|}{ 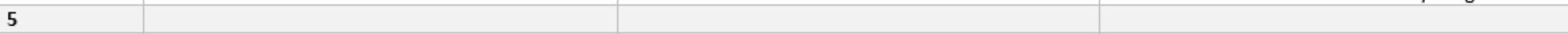 } \\
\hline \multicolumn{4}{|l|}{6} \\
\hline 7 & & & $\begin{array}{l}\text { "I mean obviously the [financial institution] is run } \\
\text { by shareholders." }\end{array}$ \\
\hline 8 & $\begin{array}{l}\text { "They're really big on making us known in the } \\
\text { community." }\end{array}$ & $\begin{array}{l}\text { "With the environment and carbon footprint, we } \\
\text { have initiatives set up for that specifically." }\end{array}$ & $\begin{array}{l}\text { "[The organisation] needs to make a profit so to a } \\
\text { point it is about making money." }\end{array}$ \\
\hline 9 & & & $\begin{array}{l}\text { "I mean we're still here to run a business of course. } \\
\text { We've got to make a profit to survive." }\end{array}$ \\
\hline 10 & $\begin{array}{l}\text { "I would see it more down this end [social] but } \\
\text { that's on the understanding that I think this end } \\
\text { [environment] is already taken care of. Because } \\
\text { that's the hygiene factor." }\end{array}$ & $\begin{array}{l}\text { "I see the environmental side almost like a hygiene } \\
\text { factor that everyone should be doing." }\end{array}$ & \\
\hline 11 & $\begin{array}{l}\text { "I see social should be a government function to } \\
\text { maintain education and that kind of thing, I don't } \\
\text { see it as such a corporate responsibility." }\end{array}$ & $\begin{array}{l}\text { "That's [the environment] something that the } \\
\text { government should be protecting, it's a public } \\
\text { good." }\end{array}$ & \\
\hline 12 & $\begin{array}{l}\text { "I would like to think that these reasons [social] } \\
\text { link directly to an individual and could help people }\end{array}$ & $\begin{array}{l}\text { "Environment I guess would directly impact on } \\
\text { social." }\end{array}$ & "In reality it's probably more economic." \\
\hline 13 & & $\begin{array}{l}\text { "I think taking care of the environment is } \\
\text { important. I'm always sceptical though as to how } \\
\text { you measure it." }\end{array}$ & \\
\hline 14 & $\begin{array}{l}\text { "Yeah, it comes in here, you know, if you're } \\
\text { looking after your people." }\end{array}$ & $\begin{array}{l}\text { "Being environmentally friendly...I think it probably } \\
\text { is a bit of tokenism." }\end{array}$ & $\begin{array}{l}\text { "We work for a [financial institution] you know, we } \\
\text { have to make a profit." }\end{array}$ \\
\hline
\end{tabular}

Label 4.3 Respondent's Perception and Understanding of CSR 


\subsubsection{Social Focus}

"It really is about getting out in the community and saying this is about us helping you as our wider community that we are in, that we just want to make an effort."

\section{- Respondent Two}

The quote above reflects many of the responses gained that identified the social aspect as an overriding component of CSR. When asked to articulate their understanding of what CSR is, 12 of the 14 respondents explicitly included social or community focused efforts of a company as an essential part of its definition. Considering the range of interpretations that were gathered as to what embodies CSR, the social aspect was the predominant response.

"The people at [the organisation] feel really strongly about giving back to the community and so there's loads of things we do from our volunteer days where we go and do time and put our skill sets back into the community but there's a lot of fundraising that happens here as well."

\section{- Respondent Seven}

This emphasis on community by employees included various groups in society such as customers, small businesses, voluntary associations and the general public. Employees that confirmed this view were aware of the community their company operated in and stated their desire to see the organisation give back to those within the same community. In addition, the size and subsequent revenue generating ability of the organisation was identified by the majority of respondents as providing the company with an enhanced capability to make a significant difference within the community. Such a recognition was accordingly used to justify their belief that the company was accountable to the wider community.

"I just feel that if they're part of a community, then they should be giving to the community."

- Respondent Fourteen

"We make a large profit that you invest in the community and they invest back in you."

- Respondent Four 
"Being able to reach out as a large entity that has a lot of money and can afford to give its employees days off to go and help somebody else, I think that's probably the most important thing that [the organisation] does as far as the CSR is concerned."

\section{- Respondent Thirteen}

Even among the respondents who noted the community and social view of CSR, personal beliefs altered how different people viewed the concept. An individual's stage of life or current situation once again played a major role in how the concept was perceived.

Respondents that agreed on the importance of the social aspect, highlighted different initiatives they viewed as more valuable or important largely based on their personal beliefs and stage of life.

"I think because your own personal life, as you mature you go through different things, different experiences and different parts of the community mean more to you at different times."

\section{- Respondent Three}

\subsubsection{Environmental Focus}

"We're such a huge user of resources that it should be our responsibility to be prudent in the use of them and protect as well."

\section{- Respondent Eleven}

The extent of responses that recognised the importance of environmental aspects within CSR was almost equivalent to that of the social aspect. Almost all responses included the environment as a characteristic of what CSR is. In identifying this area, many believed it was a fundamental element upon which CSR was initially founded and progressed from.

\section{"I think we started off here because they [the organisation] talked about carbon} credits and things like this you know."

\section{- Respondent Fourteen}

However while the majority of respondents identified the environmental factor, a great proportion of them were doubtful of its importance as part of CSR. Many respondents acknowledged that the concept has evolved beyond those components. Therefore, going beyond the simple basics of CSR was identified by respondents as a manner in which the 
integrity and genuineness of corporate behaviour is assured. As such, more than half of those who mentioned the environmental component, stated that it was important, yet not to the extent that social aspects were valued.

"What I see as the real core of a company is going, I guess, above and beyond just that hygiene factor of environmental responsibility."

- Respondent Ten

"In a lot of ways, it's like 'oh we've got bins in our offices for recycling' but for me it's more fundamental than that."

\section{- Respondent Two}

As a result, most of those participants stated the greater value of CSR activities that were directed towards social causes. In addition, the majority of employees that mentioned environmental elements also acknowledged the difficulty that surrounds the measurement of such activities and the resulting scepticism that arises.

"I'm always sceptical though as to how you measure it. So just because you put a recycling bin, you can't control what people actually put in them, you can't control if the cleaners are actually putting them in a recycling bin after you've put the bin there."

- Respondent Thirteen

"Environmental is still important but I know there's a lot of debate that it's a little fuzzy as to how important that is."

\section{- Respondent Nine}

\subsubsection{Economic Focus}

"I think a [financial institution] naturally fits more in the economic, [the organisation] is more naturally in the economic side of things, that's their skill base."

- Respondent Eleven

10 out of the 14 employees interviewed acknowledged the economic element as a part of CSR yet they were roughly evenly split on the underlying reasons why. The most commonly emerging reason for its importance was recognising the role of the shareholder. Most employees who noted the economic focus did so by placing emphasis 
on the shareholders of a company and the significance of maintaining their satisfaction with the company's operations. The respondents that explicitly identified shareholders stated their position of power and their influence. As a result these employees saw keeping the shareholders content as a responsibility of the organisation in order to maintain their own jobs, as well as to enable the company to continue making CSR oriented choices. The quote below by one respondent, sums up the common view shared by these employees that ensuring that shareholders are satisfied is an equally important component of CSR.

"If they weren't investing in the company then it would be very hard for the company to survive and therefore we couldn't give back to the environment or give back to the community or give back to the employees. So yeah I think it [economic focus] has to happen."

\section{- Respondent Nine}

Another common reason justifying the importance of the economic component is the industry in which the organisation operates. These employees recognised the business context in which their company was operating as a direct link to the significance of economic responsibility. Respondents noted the emphasis on profitability and monetary aspects for organisations operating in the financial sector and consequently perceived their organisation as being more aligned with the economic side of CSR.

"Clearly there are economics, you know a [financial institution] especially, everything's about the bottom line so you must return this money to the shareholders and must earn money in order to pay the staff."

- Respondent Four

This idea of profitability was a persistent theme with the majority of employees interviewed recognising the responsibility of corporations to make a profit, whether it be for the benefit of personal needs, shareholder needs or organisational needs. While none of the participants stated that economic responsibilities were the sole obligation of the company, the majority identified its importance in ensuring survival. 
"I guess, at the end of the day, [this organisation] needs to make a profit, so to a point it is about making money."

- Respondent Eight

\subsubsection{Industry Focus}

"Industry is an important component of CSR because as an organisation you're there for a purpose and you have expertise in a particular area. And to me, it's then actually leveraging that expertise that you have in a way that you can give that back to the community."

\section{- Respondent Ten}

Although less repeated, the specific industry an organisation operated in was explicitly mentioned by 6 people interviewed. These participants stated the nature of the sector contributed to their understanding of what constituted CSR. Such responses stated that organisations operating within the industry should seek to implement CSR initiatives that take advantage of their specialised area of knowledge and skill.

"Because at the end of the day, if we have the skills within the organisation, it's about saying actually we can't just look after ourselves and look after our customers, we need to get out there because we are responsible for improving the general financial literacy of the country."

\section{- Respondent Two}

The responses specifically identified the financial industry their organisation was operating within and defined their expectation of CSR with regards to this. Respondents recognised their organisation's area of expertise lay in financial knowledge and many stated their view that CSR should incorporate activities such as the provision of financial information and assistance to the community. Others, though not specifying the type of CSR initiatives they deemed acceptable, noted the typical high profitability of firms operating in this sector. Consequently, the need for such profits to be given back in the form of community initiatives was heightened among these employees. 
"You have to take care of other people. I think that's important and if you can afford to do so, even more should it be an onus on you to do it."

- Respondent Thirteen

"I think it's always tricky when you work for a [financial institution] and they make huge profits and you know they're here to make huge profits but I still think it's really important that they're seen to be giving it back in a variety of areas."

- Respondent Fourteen

In addition, 8 of the 14 respondents interviewed specified the size of the organisation as directly impacting upon their understanding of CSR. While the overall view deemed that CSR was important to any organisation regardless of its size, these respondents noted the ability of size to influence the subject. However, views were divided in regards to the manner in which it influenced CSR. The greater proportion of these responses stated that the larger an organisation is, the greater the obligation of that company to be socially responsible. These participants acknowledged the cost of implementing CSR and thus concluded that a larger firm had a greater capacity to do so. In addition, a larger company typically includes greater number of employees and this was acknowledged as further ability to use their man power to make a difference in society.

Particularly with big companies, they have lots and lots of employees, it's the power of having that many people. Because we have so many people here, we've kind of got a big scope to do that. Like something little makes a big difference."

- Respondent Seven

A small number of respondents had a different perspective, stating that a smaller organisation had a greater ability to promote internal CSR. Valuing staff and creating a strongly connected team environment within the organisation was noted by these employees as significantly harder, or near impossible, in a larger corporation as opposed to a smaller one.

"In a smaller organisation it's easier to create a family but in a large organisation I can imagine that's quite hard."

- Respondent Eleven 


\subsection{Influences of CSR on Belongingness}

There was a wide range of responses in how CSR might influence or impact upon an individual sense of belonging. Despite some disparities in their feedback, most participants shared an understanding that the CSR activities of their company contributed in some form to their sense of belonging. The manner in which this was achieved for each individual varied yet there was a significant degree of consensus that led to the emergence of common themes and recurring patterns in the data.

\subsubsection{Awareness}

"Yes I think so. I think awareness plays a big role in how employees are affected by CSR."

- Respondent Nine

First and foremost, 8 of the 14 participants agreed that awareness of the company's initiatives played a key role in how and the extent to which the concept impacted on an employee. Participants noted that simply being aware of the CSR of their company has the power to influence the manner in which it is perceived by an employee.

"Awareness of what kind of things [the organisation] is doing definitely contributes to how I feel about CSR."

- Respondent Eleven

In raising the issue of awareness, employees that identified this also recognised the role of position and level within the organisation. Lower level employees noted the comparatively increased need for awareness as their preoccupation with routine daily obligations often means they overlook the availability of other activities to get involved in.

"I want to be involved and part of it's just me seeing what's out there too and actually how it works."

- Respondent Twelve 
Most of the respondents also noted the role communication plays in increasing awareness among employees. Participants recognised the impact of technology with several respondents mentioning the use of company websites and intranet facilities as a vehicle for management to communicate information about CSR to employees. Respondents noted the availability of such methods to enable greater amounts of knowledge to be passed through levels of the organisation. In addition, a few employees also revealed their ability to take advantage of such technology to publicly share personal CSR related initiatives and programs amongst colleagues.

"On our intranet site, you see a lot of people posting on there what they're doing. I guess it just became a lot more acceptable and a lot more public."

- Respondent Thirteen

One respondent specified that it is the concept of communication itself that has evolved. Although this wasn't a widespread view voiced by respondents, this employee stated that the nature of communication has changed, in that it is no longer pushed and forced upon people but it is the people who actively seek the information. While only one respondent specifically identified this development in communication, this view was justified by other participants that noted the extent to which the organisation made its CSR policies and initiatives public knowledge amongst staff. This was reiterated by numerous employees who stated the availability and access to such information sent the signal that CSR was worthwhile and consequently promoted the idea among workers.

"One of our key areas about [the organisation] is CSR. So we make a lot of information available for people who want to go see what the [organisation] per se is doing in that area."

\section{- Respondent Ten}

However, a minority of the participants also identified its reverse influence. A small number of employees were candid about what they perceived as the lack of awareness promoted and facilitated by the organisation. Some respondents attributed this to the organisations failure to communicate internal knowledge regarding CSR policies and strategies to workers as effectively as it presents successful outcomes of initiatives to 
the public. However, another respondent acknowledged that perfect awareness of a company's CSR practices is near impossible due to the sheer amount of information available.

"I don't think that any employee hand on heart could ever say that they know everything that [the organisation] is up to, cause we wouldn't."

- Respondent Eight

\subsubsection{Pride in Organisation}

\section{"I do believe there's a sense of pride in knowing that my company's pretty cool."}

- Respondent Thirteen

From the employees interviewed, one of the most commonly agreed upon

consequences of CSR was its ability to enhance a sense of pride. Almost all responses to how CSR influenced a sense of belonging in each individual incorporated the pride they felt for the company. 12 of the 14 employees reflected on the development of a sense of pride in the organisation that ultimately built a connection or bond with the company. A sense of pride was a feeling shared by most respondents, yet the way it was perceived and understood by individuals, varied to an extent.

Undoubtedly the most common view shared by almost all respondents was the effect of the company's involvement in the wider community. The initiatives that were undertaken by the company and known to making a difference within society was repeatedly identified as a source of pride in being associated with such an organisation. Most responses tended to encompass any initiative that benefited the general society. However, the few that mentioned CSR practices specifically, were more inclined towards socially responsible tactics as opposed to environmental initiatives with the latter not identified explicitly as establishing a sense of pride among employees. Actions directed towards giving back to the community and benefiting the people within were expressly noted as something employees were proud of.

"I just feel proud that the [financial institution] participates in these types of things. I'm proud to say I work for [the organisation] because of these things."

- Respondent Five 
Most respondents also referred to personal values and the pride that arises when these are aligned with company values. These employees indicated their pride in the organisation was a result of being publicly associated with an organisation that holds similar beliefs to themselves. Initiatives carried out by the company that are in line with what the individual personally views as important created a sense of solidarity with the organisation and thus led to building a sense of pride. Participants noted the sense of gratification that was felt when employees come to the realisation that their job supports their own personal beliefs within the community.

"Being involved in the wider community, it's just a truer expression I guess and um gives you a greater sense of pride for the company that you align yourself with that you work with."

- Respondent Twelve

Some respondents also highlighted external appreciation and its contribution to an overall sense of pride. While the majority of participants credited their pride to the actions of the company alone, a few went further to claim their satisfaction resulted from outside recognition of their company's practices, further enhancing the sense of pride. As such, respondents specified the idea that the positive organisational culture created by CSR relayed to groups outside the company, resulted in a sense of pride amongst employees.

"I think for us permanent staff that we notice it a lot when contractors come in and out of [the organisation] and just about in every single case, the contractors will comment on the fantastic culture that we have but also the willingness of people to get out and do things in the community and the way [the organisation] thinks about things here. They'll say it's quite unique. And then that of course makes you feel proud again and makes you want to maintain it."

- Respondent Seven

"I think more so when I speak to people outside of [the organisation] and they say 'oh yeah we had a team from your work and they did this and that was really cool that [the organisation] does that' and I think in that sense you feel a sense of pride."

- Respondent Thirteen 


\subsubsection{Employee-Driven Initiatives}

"It's encouraged that every week there'll be something that someone's doing for something."

\section{- Respondent Three}

Regardless of whether it specifically influenced a sense of belonging for them or not, all respondents identified the organisation as promoting and encouraging initiatives that come from the bottom up. Participants were very forthcoming of the organisational culture that has allowed employees to present their own ideas of what constitutes CSR and how to go about it. The majority of respondents took this a step further by affirming such employee-driven CSR has the ability to influence their sense of belonging within the organisation. This particular view was emphasised throughout the data with all but 3 respondents explicitly acknowledging its influence over their sense of belonging.

\section{"I like to see that the organisation does it but also the individuals within the} organisation take the initiative as well. So you know it's those people that you think, yeah they're the type of person to want to work alongside."

\section{- Respondent Fourteen}

The management structure of the organisation was a frequently repeated subject amongst participants, and was used by the majority to highlight the bottom up approaches that have been taken when it comes to CSR. Many respondents emphasised that the organisation enabled and empowered staff to launch personal initiatives throughout the company. Accordingly, these responses also identified the power of such policies to foster a sense of belonging. Interviewees were increasingly responsive to initiatives that emerged from employees themselves as opposed to the detached manner in which they are pushed down from top management. Participants stated this bottom up approach created a supportive environment where they felt comfortable to bring forward their own suggestions and ideas.

"I think CSR is really important as a tool for making employees feel an attachment but it's interesting because I don't know if you achieve the same result if it's CSR coming down from up on high as you just really get naturally once it's coming from the bottom 
up."

\section{- Respondent Ten}

In addition to fostering a culture where employees felt free to bring their ideas forward, most of the respondents elaborated further to state that employee-driven initiatives also established a sense of community and comradery between colleagues. Responses stated the amount of initiatives that originate from grassroots have not only increased but become accepted as part of normal organisational culture. As such, responses repeatedly included staff members' willingness to participate and get involved in a colleagues personal initiatives and activities.

"You know that people will always support an initiative. Any time I go up for volunteers I'm always surprised at how quickly and how people are really willing to support different activities."

\section{- Respondent Three}

Encouraging and promoting such a culture was also addressed as paving a way for employee buy-in to be further augmented throughout the organisation. This concept, also addressed as employee participation, was identified by several respondents as a significant contributor to the success of CSR and one that emerges as a result of the normalisation of employee-driven initiatives. The work environment that promoted and supported grassroots initiatives was recognised as developing an acceptance of CSR amongst employees. The company's attribution of value to personal employee-driven initiatives was identified as strengthening an employee's willingness to participate in overall CSR. Ultimately the five respondents that shared this view, stated that increasing employee participation was necessary in order to generate momentum and continuously increase CSR. However they also noted its implications for belongingness through the sense of inclusion it promotes throughout the organisation as well as contributing to a culture acknowledged as encouraging and supportive.

"Employees taking on initiatives themselves, to me that's when you've reached a certain level of maturity because you haven't got anyone from up high hoisting things on the organisation. You've actually got people who are passionate about things 
themselves who are reaching out to the community."

- Respondent Ten

"Being in an environment that values the internally organised and internally brought up, I feel quite easy to get involved and to participate."

- Respondent Twelve

"It's more of a reality than anything else that you need to work for something bigger than yourself. If you don't work for something bigger than yourself then at the end of your life, you go to your grave, what else is there?"

- Respondent Six

While these respondents reiterated their positive perceptions of employee buy-in, few also conveyed their understanding that such a view is not widely accepted or shared by all employees. As one participant noted, although the organisation boasts a general culture of CSR and grassroots initiatives, each individual is different in the manner and extent to which they are influenced. Two responses addressed the possibility that not all their colleagues feel the same way, or are not influenced to increase their willingness to become involved beyond what is required of them.

"I would love to see more stuff in the community. But an employee who may not have any CSR interest as such would probably just do what they've been told. Because I know there's people that hate doing the CSR because they would much rather just work, or it's not their bucket. I think they just couldn't care less really."

- Respondent Thirteen

"You'll get some people who won't like certain things or don't think that you should be involved in certain things."

- Respondent One

Respondents also stated that employee-driven initiatives projected CSR in a more genuine and authentic light as opposed to practices that were enforced from the top. Interviewees recognised that the nature of employee-driven initiatives means they are not actively promoted or excessively publicised by executives. In addition to providing "good vibes" in the working environment, respondents expanded further in saying that 
the employee-driven initiatives provides a more authentic illustration of the company's values. These activities are accepted and encouraged though no publicity is gained by the organisation as a result.

"They're not trying to leverage, they're not maximising the PR that they could and so that makes me think yea that's [employee-driven initiatives] more genuine. They really care so much for the little things."

\section{- Respondent Twelve}

Expanding from employee-driven initiatives, almost all respondents recognised the additional influence of leading and implementing practices of personal significance. In accordance with grassroots initiatives, participants emphasised the positive consequences from being able to bring forward initiatives that they hold in high value personally. Respondents justified this notion in a variety of ways; the most common, being the inclusive culture it fosters. It is indicative of an accepting environment which in turn, increases a feeling of belonging to the corporation. The other common reasoning for improving a sense of belonging is the opportunity for employees to be themselves at work. Interviewees mentioned the ability to bring forward personal initiatives allowed them to express themselves more freely at work and be encouraged to do so.

"I think that you've got a lot of opportunities to get involved personally and bring your own outside interests into that. And that definitely gives you more overall inclusion."

- Respondent Eleven

\subsubsection{Colleague Relationships}

"It's all done through the colleagues. So the colleagues become the collective."

- Respondent Six

Another theme illustrated by 10 of 14 responses noted the value of colleague relationships to enhance a sense of belonging to the organisation as a whole. This was justified through the prevalent view amongst interviewees that colleague relationships held the ability to create a sense of unity and comradery. A few respondents elaborated further to identify that the influence of colleague relationships is strengthened when it extends beyond purely work related tasks. A deeper connection was established with 
colleagues when founded on something more personal such as CSR practices where they work together to make a difference, as opposed to a purely professional relationship.

"Where people have worked really well, it's always been driven by a shared sense of purpose but I think you get that deeper connection when it's something personal rather than something that's work related."

\section{- Respondent Ten}

This personal level was reiterated with respondents stating their ability to engage with other staff members and ultimately promoting a sense of inclusion. CSR was identified by respondents as a tool that enabled new connections to be made, and to strengthen existing relationships. Participants emphasised the CSR initiatives implemented by the organisation that required employees to collaborate and achieve an outcome. They recognised that the nature of CSR enabled them to take part in activities outside of their work obligations and accomplish goals that make a difference in the community with the people they come to work with every day. These employees were in agreement that such activities not only facilitated more meaningful relationships with colleagues, but also had positive implications for the organisation in that the culture was enhanced and people felt more happiness and satisfaction in their job.

"I think it's really good for the people that work here, because what it does is that you get a group of people that go out and do something together. So you get to know each other a bit more and I think that in itself makes the culture at work a better place."

- Respondent Seven

Some participants narrowed their responses to specifically identify the interactions between colleagues. These interviewees stated that the organisational wide CSR activities had the ability to bridge gaps between different teams and departments and ultimately bring the organisation together, particularly where CSR initiatives facilitated interaction between employees of all levels and positions throughout the organisation. The majority of employees acknowledged the ability to expand outside their usual work boundaries and meet new co-workers in a non-working environment that subsequently allows for deeper bonds to be made and create a sense of belonging. 
"So it's much wider than just me and my small team doing something."

- Respondent Three

"Going out and doing things as a group because you're meeting people in the organisation, people you wouldn't normally meet, wouldn't come across because your jobs don't connect with each other."

- Respondent Fourteen

\subsection{Overleveraging Value of CSR}

"I think sometimes it's like to be 'seen' to be doing something. Rather than actually wanting to do something. Like 'oh yeah I'm getting involved in this, there will be some advertising and that will be good for the company' instead of like 'hey what's it doing for the community?"”

- Respondent One

Sections 5.4 - 5.5 have recognised the influence of CSR on an individual's sense of belonging in a positive sense however, there were instances of negativity that must be noted. These opposing views illustrate the employee's desire for balance. All respondents identified the positive impact CSR can have on their sense of belonging within the organisation, albeit in a manner of different ways. However, a prerequisite for belongingness that was recognised by the majority of respondents, was genuineness of the company's CSR efforts. 10 of the 14 employees interviewed expressly mentioned the need for authenticity in order to feel a sincere attachment to the organisation. These responses emphasised that it wasn't just the implementation of CSR initiatives, but the genuine intention behind it that fosters a sense of belonging. The sincerity on behalf of the organisation was thus related to the extent to which these employees felt a bond with the company.

"It has to be authentic every single time otherwise people will just do it, but only because they've been told to do it as opposed to understanding why."

- Respondent Seven

"CSR is not something I would look for in terms of a word. Because I think a lot of people can put that on their mission statement or say that it's their value but it doesn't 
necessarily mean that it is."

- Respondent Three

Within the responses that identified the widespread need for genuineness, a smaller proportion of the participants recognised a trade-off that arises in regards to CSR. These employees stated that while the existence of CSR initiatives indicated the values of the company and thus created a sense of belonging, overzealous publicity of these same activities can generate a backlash. The public leveraging of the corporation's efforts was acknowledged by some participants as having the potential to undermine the value of such activities and as a result, the impact it has on the employees.

"The other side of it is that there is the potential to feel cynical. So if there is the feeling that something is being done under the guise of CSR but it's really to get brownie points for the company, 'look how good they're doing' then to me that kind of backfires. I think oh that company is just doing something to get a good name or something rather than really believing in it."

- Respondent Ten

Such a view was indicated up by over half of respondents that classified such behaviour as greenwashing and noted its negative impacts. These employees noted their positive response to CSR when implemented for the right reasons but also its equal potential to inflict negativity if motivated by contradictory reasons.

"I think CSR is a tool that can be used either way, and it can cause damage if it was found out, or proven, or suggested, with sound reason that it was actually motivated by different financial or PR reasons."

- Respondent Twelve

"It's about how you act without an audience, not only when somebody's watching."

- Respondent Two

As a result, these interviewees recognised the double-edged nature of CSR. The prospective benefits could not be sought after at the expense of authenticity, which was deemed by the employees as equally important in enhancing a sense of belonging within the organisation. A genuine intention for implementing CSR was recognised to be just as 
important as the initiative itself for many of the respondents. However some respondents did note that ultimately, it was the outcome that mattered. This was not a widely provided response, yet the two employees with this view, noted that while genuineness was valued, the benefit to the greater community could outweigh a lack of sincere intentions.

"I think if a company is acting ethically, for whatever their motivators are, I think it's a good thing. So I will probably see them in a positive light anyway."

- Respondent Thirteen

"You can still do the right thing for the wrong reason and still have a good outcome."

- Respondent Twelve

\subsection{Other Potential Influences of CSR on Belongingness}

In addition to these common themes, there were other less highlighted factors that are potentially influential to understanding how CSR can influence an employee's sense of belonging. These ideas were not repeated by many other respondents and therefore are grouped here under other potential influences.

\subsubsection{Employee Loyalty}

"Certainly makes me feel more loyal to them [the organisation] and a sense of 'yeah I want to give back for that investment they're putting in.'”

- Respondent Twelve

Mentioned by 2 of the 14 employees during the later interviews, these responses elaborated on the connection that was formed within the organisation through loyalty. One interviewee focused specifically on internal CSR policies aimed at benefiting employees and the consequent loyalty that was created as a result of feeling valued. This response included the notion of reciprocating the investment the organisation has made in the employee themselves through ongoing loyalty to the employer. This particular respondent noted their willingness to stay with the organisation came from this sense of feeling valued. The other, however, spoke of CSR initiatives in a general sense and the loyalty that was established due to knowledge that their employer showed a 
commitment to CSR. This particular response focused on the loyalty that arises from knowing their organisation supports such initiatives and practices.

"I think ultimately if the company is being responsible socially, then I think it does create loyalty among its employees."

- Respondent Eight

\subsubsection{Skill Development}

Another factor potentially influencing an individual's sense of belonging was the ability to take something away from the organisation. 3 of the 14 participants acknowledged their sense of belonging was impacted on by what they have been able to personally gain from the organisation. All three responses highlighted the enhanced sense of belonging that came from the organisations various CSR activities and policies that had an effect on each individual personally. With regards to attitude, behaviour and communication, the interviewees stated the personal improvements that were developed in a working environment that promoted CSR initiatives. Specifically, 2 respondents spoke of the interaction and networking skills that were gained from working closely with multiple groups of people and the overall increase in confidence. The opportunity to improve personally through the organisation's commitment to helping society subsequently reinforced their connection with the corporation.

"It gave me a bit more confidence because I had to interrelate and deal with different people and different parts of [the organisation] that I don't normally deal with and also deal with the external charity person that I wouldn't have known otherwise."

- Respondent Nine

The other employee specified other ways in which they felt personally enriched. This particular response included the effects of working in an environment where CSR activities are consistently encouraged and promoted, by management as well as by colleagues around them. This participant recognised the subsequent impact personally changed their outlook and perspective on CSR as well as its application to their life outside work. Such personal impacts were recognised by the employee as establishing a bond or sense of attachment to the company and thus strengthened their sense of belonging in the workplace. 
"I've boosted up my volunteering effort outside of work. So it's [CSR initiatives] made me think about myself as a member of society a bit more. You see people around here, there are some saints here who you know every minute outside of work they're out doing something for someone else, and that's made me feel that I should up my game. Yeah made me a better person outside of work."

- Respondent Eleven 


\begin{tabular}{|c|c|c|}
\hline $\begin{array}{l}\text { Influencing } \\
\text { Factor }\end{array}$ & Example Quotes & Respondents \\
\hline Awareness & $\begin{array}{r}\text { "I certainly think that as an employee, understanding what an organisation does in } \\
\text { relation to CSR, can have a big impact on how you think about that employer." } \\
\text { - Respondent } 10 \\
\text { "I definitely think that at the end of the day, some things get lost." } \\
\text { - Respondent Eight }\end{array}$ & $\begin{array}{l}4,8,9,10 \\
11,12,13 \\
14\end{array}$ \\
\hline $\begin{array}{l}\text { Pride in } \\
\text { Organisation }\end{array}$ & $\begin{array}{l}\text { "It kinda makes you feel proud when you can actually work for somewhere and you can } \\
\text { sort of say, these are things that we're doing." } \\
\text { "I feel proud of the [financial institution]. I feel proud to be supported by the board. } \\
\text { There's nothing better than that." } \\
\text { - Respondent Four } \\
\text { "There is that sense of pride, if you like, to work for [this organisation]." } \\
\text { - Respondent Six }\end{array}$ & $\begin{array}{l}1,3,4,5,6 \\
7,8,10,11 \\
12,13,14\end{array}$ \\
\hline $\begin{array}{l}\text { Employee } \\
\text { Driven } \\
\text { Initiatives }\end{array}$ & $\begin{array}{l}\text { "Knowing the company I work for is supporting something I personally believe in, } \\
\text { encourages me to want to be in the [organisation] family as such." } \\
\text { - Respondent Nine } \\
\text { "Knowing I can bring my personal beliefs in, I mean that's really good, it gives you a real } \\
\text { sense of inclusion um and it gives you also a real sense of that the organisation, um that } \\
\text { the culture is one of acceptance." } \\
\text { - Respondent Ten }\end{array}$ & $\begin{array}{l}3,4,5,7,8 \\
9,10,11,12 \\
13,14\end{array}$ \\
\hline $\begin{array}{l}\text { Colleague } \\
\text { Relationships }\end{array}$ & $\begin{array}{l}\text { "I think it's good that as an organisation I can work with people I never worked with and } \\
\text { do something good for the community, whatever that is." } \\
\text { - Respondent Six } \\
\text { "And you know there were some teams in particular who will be quite isolated or maybe } \\
\text { even on some lower pay grades, but they can really be involved and lead that kind of stuff } \\
\text { and they feel really engaged in doing that." - Respondent Three }\end{array}$ & $\begin{array}{l}3,4,6,7,8 \\
9,10,11,12 \\
14\end{array}$ \\
\hline $\begin{array}{l}\text { Overleveraging } \\
\text { Value with } \\
\text { Stakeholders }\end{array}$ & $\begin{array}{l}\text { "I'm being quite sceptical and pessimistic but at a corporate level, they need to look good } \\
\text { so I feel like the motivation is often for that market perception." } \\
\text { - Respondent Twelve } \\
\text { "That's where you get the trade-off of 'yea we're supportive but we're going to tell } \\
\text { everyone about it so that we get the good kudos for it." } \\
\text { - Respondent Ten }\end{array}$ & $\begin{array}{l}2,3,7,10 \\
12,14\end{array}$ \\
\hline $\begin{array}{l}\text { Lessons Taken } \\
\text { Away }\end{array}$ & $\begin{array}{l}\text { "Yea cause I mean at the end of the day if I was ever to move into another organisation, } \\
\text { there would probably be a lot of positive things that I would've learned from [this } \\
\text { organisation] and some of them even subconsciously." } \\
\text { - Respondent Eight. }\end{array}$ & $8,9,11$ \\
\hline $\begin{array}{l}\text { Employee } \\
\text { Loyalty }\end{array}$ & $\begin{array}{l}\text { "Like I appreciate and I value the effort that they've made and it certainly makes me feel } \\
\text { more loyal towards them." } \\
\text { - Respondent Twelve }\end{array}$ & 8,12 \\
\hline
\end{tabular}

Table 4.4 Summarised Factors Influencing Belongingness 


\section{DISCUSSION AND IMPLICATIONS}

This thesis sought to understand the nature and extent to which a company's CSR activities influence an employee's sense of belonging. Through a qualitative study of a single organisation in the financial services sector within the Wellington region, a variety of mechanisms that affect this relationship were identified.

Earlier chapters discussed the rising importance of both a sense of belonging and CSR for employees within the workplace, identifying the potential benefits both to the individual and the organisation as a whole. While an organisation's role in fostering a sense of belonging amongst its employees has been highlighted, and societal views that they contribute in a socially responsible manner have increased greatly, the relationship between the two concepts remains relatively unexplored.

This discussion chapter will contrast the existing literature with the findings arising from this study to look into the relationship between the concepts in more depth. It explores the more common factors underlying this relationship to provide greater understanding of how an employee's sense of belonging may be influenced through the implementation of CSR initiatives. In addition, the wider research and managerial implications of the findings are considered, including the scope for future research. Finally, some limitations of the study are acknowledged.

\subsection{Results Framework}

As presented in the earlier findings chapter, themes were extracted from the data on the basis of their recurrence and significance to understanding the relationship under study. While these themes have been presented separately, they can be drawn together to highlight their interconnections and illustrate interdependencies between them. The framework developed and presented below illustrates these linkages. In doing so, a more holistic understanding of the nature and extent of the relationship between CSR activities and an employee's sense of belongingness is possible. 


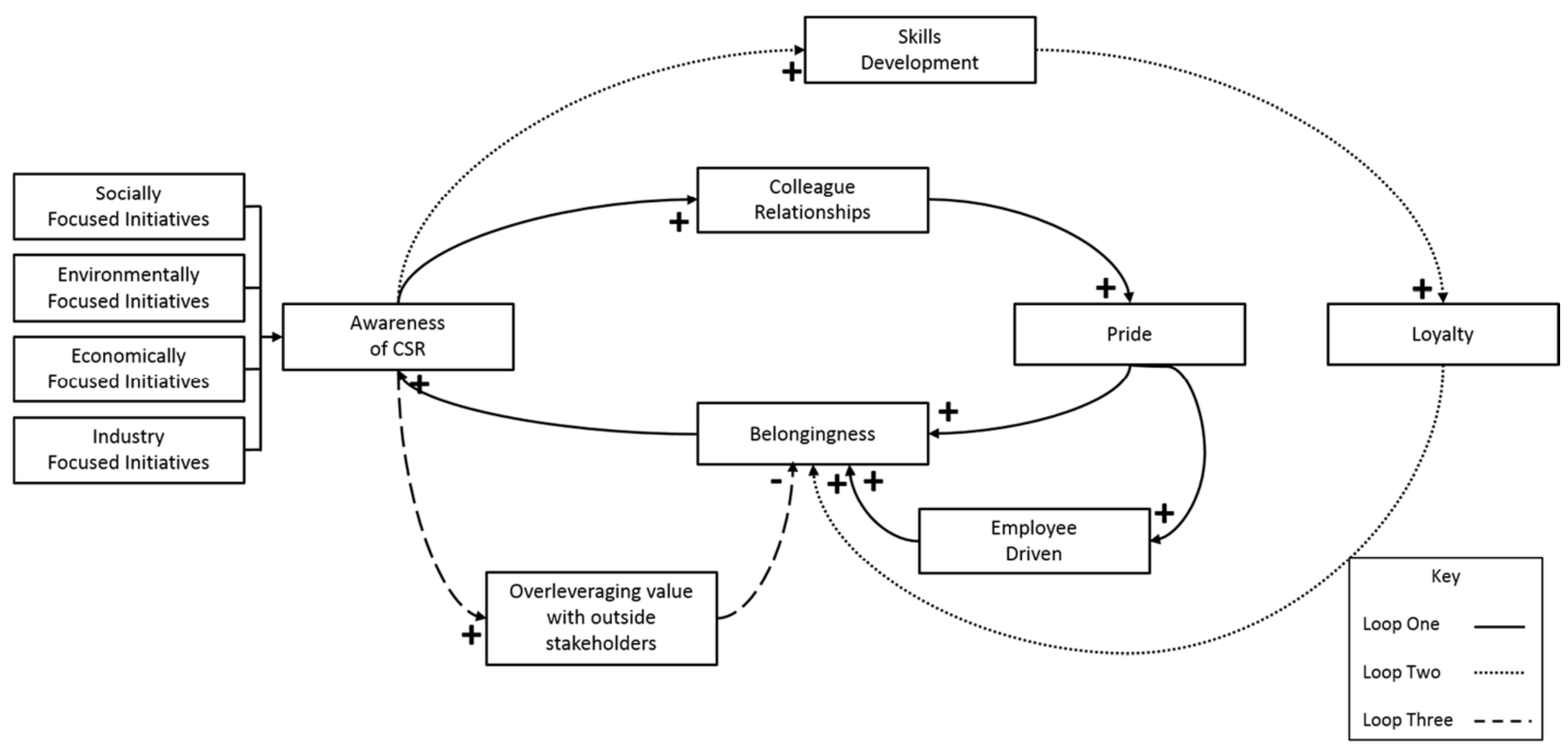

Figure 5.1 Emergent Themes of CSR Influence on a Sense of Belonging 


\subsection{Loop One: Primary Influences on a Sense of Belonging}

Loop one in the diagram depicts several of the main recurring themes from the data. Not only were these the most common, but further analysis uncovered interrelationships between them that ultimately enhanced understanding of how, and the extent to which CSR could influence an employee's sense of belonging.

From the outset, awareness of CSR activities was identified by respondents as being a necessary condition in order to be influenced by their actions. This view is in accordance with numerous studies that have identified awareness as an antecedent in determining the extent to which an employee can be influenced by CSR (Gond et al., 2010). Consequently, its characterisation as a fundamental building block throughout literature (Stawiski et al., 2011), was reflected here with the concept repeated by the majority of respondents. As such, the significance of the relationship between CSR and the awareness of employees was further emphasised. Without this inherent awareness, it is unlikely that employees will then become influenced by the activities that the organisation undertakes. The importance attributed to this relationship by respondents, corroborated the existing literature that asserted that employee awareness outweighed the CSR initiatives itself (Ellis, 2009). As a result, it can be inferred that although CSR initiatives may be adopted, without ensuring employee awareness, its potential to influence employees will not be sufficiently utilised.

The significance of the relationship between CSR and awareness was further illustrated by employees down the hierarchy. These respondents acknowledged their limited knowledge of CSR initiatives was largely due to their preoccupation with the specific daily activities their role demands. With comparatively more laborious needs, the flexibility to actively search for opportunities to learn and become involved in CSR practices was limited. As such, this exemplifies that although various CSR initiatives were being implemented, its influence over these employees was limited as a result of their unfamiliarity with the activities. This tendency to overlook lower level employees' comparatively limited knowledge of CSR strategy and operations have been previously identified in literature (Stawiski et al., 2011). As such, the importance of awareness is highlighted as these employees have indicated their desire to be a part of CSR, if the opportunities are made available to them. Consequently, with research identifying the ability of awareness to enhance an individual's association with 
their employer (Chong, 2009), these results highlight the potential of awareness to foster a sense of inclusion among employees of all levels.

Increased awareness of CSR initiatives not only provides employees with the opportunity to get involved in the activities, but also to use these as a platform to build social relationships with colleagues. The diagram illustrates this by recognising the positive flow-on effect that increased awareness can have on colleague relationships. The majority of respondents that emphasised the importance of CSR to develop colleague relationships suggests that a sense of community amongst employees can be built on the foundation of CSR. As such, the more an employee is aware of the CSR activities throughout an organisation, the more they are able to capitalise on its potential to build a bond with co-workers. Respondents elaborated to specify the importance of personal relationships, extending beyond the boundaries of work related interactions which suggests a desire to engage with colleagues on a deeper level. In defining a sense of belonging, previous studies have recognised that the formation of relationships do not necessarily guarantee a sense of belonging, but rather, it is achieved through the acceptance and support of their social group (Hagerty et al., 1992). As such, the value placed on personal relationships indicates they are more likely to facilitate a sense of inclusion amongst individual employees as opposed to the mere obligatory work relationships. Therefore, in this context, CSR provides this opportunity for employees to collectively work towards, and achieve a goal outside of their job descriptions of professional obligations. Such a realisation is made possible with employees increasingly being made aware of the CSR initiatives they are able to collaborate on with colleagues. Consequently, employees have the ability to develop the more deep-rooted connections with co-workers that they may be seeking.

Respondents also noted the ability of CSR to bring together an organisation as a whole. Alongside seeking for more personal relationships with workers, participants acknowledged the desire to interact with a wider range of colleagues from across the organisation. Whereas work-oriented objectives require collaboration between an employee's specific team or department, CSR provides the opportunity to break these boundaries and connect with a variety of employees. Expanding on the meaningful relationships, previous research has identified its connection to the idea of group membership (Van Prooijen et al., 2004). Subsequently, a sense of membership was asserted as representing inclusion within a larger entity (Lambert et al., 2013). As such, the ability to forego an employee's specific role and 
authority in regards to CSR initiatives, provides the opportunity to develop a sense of comradery amongst staff and ultimately, a sense of inclusion throughout the organisation. This was noted as particularly significant for respondents who acknowledged that the large size of the organisation inevitably limits the extent of interaction amongst workers. Consequently, CSR activities can be seen as a tool to compress a growing organisation. The benefits of creating and strengthening colleague relationships also extended to creating a sense of pride amongst workers. As the most repeated factor throughout the data, a sense of pride was mutually highlighted by almost all respondents as a significant component of the relationship between CSR and a sense of belonging. The encouragement of colleague relationships through CSR activities fostered a culture of acceptance and inclusion within the organisation that was made visible to external parties. The resulting positive reputation established for the company was identified as a source of pride by employees. The more this culture was promoted throughout the organisation, the more the company was viewed favourably by outside parties. This positive public image has been recognised in existing literature as fostering a sense of pride for employees who associate with the organisation (Brammer et al., 2007). This significance of external judgement has been repeated throughout literature with numerous studies reiterating the crucial role of external stakeholder impressions (Gond et al., 2010). As such, the results suggest that increasing colleague relationships and the culture it fosters has a positive influence over how the organisation is perceived externally and thus stimulates a sense of pride for employees associated with the company.

The idea that external views of the company can result in an employees' sense of pride alludes to the notion in the literature, that external CSR can be positively correlated to an internal stakeholder (Peterson, 2004). Although the colleague relationships and culture established are primarily internal CSR initiatives, the responses are illustrative of Peterson's (2004) study in that a favourable reputation of the company, enhances employee morale and commitment. As such, the influence of a sense of pride on an employee's belongingness begins to provide understanding of the relationship between external CSR and employees, which was previously identified as lacking in the literature (De Roeck et al., 2014). In addition, this idea is highly reflective of the construct of belonging, Social Assurance, mentioned in Chapter Two, where a sense of belonging for an individual was measured on the assurance they receive from external sources (Lee \& Robbins, 1995). Consequently, an 
increase in colleague relationships can result in an increase in the assurance an employee will receive from external parties upholding a positive view of their employer. The greater the level of assurance employees receive the more they are able to affirm their belonging to their external surroundings of the organisation. As such, developing a sense of pride in the organisation has the potential to instil a sense of belonging in employees.

However, in addition to a fostering a sense of belonging, employee pride was also found to have an additional influence in regards to employee-driven initiatives. As respondents attributed a sense of pride to the positive organisational culture linked to CSR, participants similarly expressed that this also facilitated the emergence and rise of employee-driven initiatives. Interviewees identified the culture of acceptance and inclusion that was established was enhanced and complemented through the bottom up, flexible management structure that was promoted in terms of CSR.

This management structure was elaborated upon further by all but three of the employees, with this approach seen as paving the way for grassroots CSR to emerge and increase. The culture established through the flexible structure was repeatedly drawn upon by respondents to explain the comfort they felt in bringing forward personal ideas or initiatives in relation to CSR. Previous research has addressed the rising stakeholder expectation that the organisation demonstrate values that are consistent with their own (De Roeck et al., 2014). However, while existing literature has identified this importance of the congruence between organisation and employee values, it has primarily been discussed in determining an individual's perception of CSR (Gond et al., 2010). This study found that an environment that both allowed, and actively encouraged employees to introduce personal initiatives not only influences their perception of CSR, but ultimately increased their identification with the entity. Therefore, fostering a sense of pride amongst employees and developing a culture of acceptance and inclusion can be seen as a mechanism to encourage employee-driven initiatives.

An additional follow on effect of this work environment is an increased willingness to participate and become involved with CSR. Previous research has addressed the ability of employee participation and engagement with the organisation, to enhance a sense of belonging (Benson \& Dundis, 2003). In accordance with this view, the more an individual is able to implement personally-driven initiatives through the organisation, the more likely they will be inclined to participate. Whereas broad executive-driven activities have the 
potential to be received cynically or carried out begrudgingly, respondents noted they are more likely to become involved in activities that have personal value. Furthermore a culture that allows employees to see initiatives originating from their colleagues have increased their willingness to volunteer and participate as means to offer assistance to their friends and fellow workers. Ultimately, the consequences of such a culture leads to employees increasingly becoming involved with CSR, thus developing a stronger bond or connection to the organisation.

The emphasis placed on grassroots initiatives by respondents suggest that employees can be seeking to express their true identity in the workplace. Responses identified that personallydriven CSR activities can be seen as a means through which this individual desire can be fulfilled. As such, it is illustrative of the concept of Organisation Identification, whereby employees perceive an alignment of their personal and organisation's characteristics (De Roeck \& Delobbe, 2012). Consequently, employee-driven initiatives have the potential to further augment and strengthen an individual's sense of belonging. Ultimately, the emerging themes and interrelationships between them present a form of a virtuous cycle that promotes and enhances an employee's attachment to the organisation.

\subsection{Loop Two: Supplementary Influences on a Sense of Belonging}

While the main recurring themes form Loop One, the comparatively less repeated themes surfaced from the data revealed insights into another relationship between CSR and an employee's sense of belonging. Although these findings form a separate loop, it is important to note each loop in the diagram is not intended to appear mutually exclusive but rather are likely to be complementary and interconnected.

While earlier sections discussed employees gratitude for the opportunity to bring a personal idea or initiative into the organisation, a few respondents acknowledged the chance to take something away. The belonging literature has examined the influence of a sense of belonging to improve employee self-esteem, productivity and performance (Alam \& Rizvi, 2012; Rego et al, 2009). However, there has been limited attention as to how CSR can influence an employee's personal development. The skills development through the implementation of CSR was an idea not widely noted by participants, but it contributed a novel linkage to the understanding of its relationship with a sense of belonging. The responses incorporated the ability to develop leadership, communication and social skills 
that were specifically recognised to be enhanced through the characteristics of CSR. The interaction and networking skills in working with multiple groups of people, as CSR typically requires, thus provides employees with the opportunities to build confidence in such skills. Therefore, an enhanced awareness of CSR throughout the organisation, provides more potential for employees to develop skills and a sense of accomplishment.

That employees were able to develop skills through the company's CSR, illustrates that such initiatives can foster and encourage substantial employee involvement and commitment, leading to further identification with the company. In addition, there is also the potential for CSR to develop skills and a desire to become personally involved in acts of benevolence towards the greater community. As such, the more an employee is consciously aware of CSR practices, the more the individual would be expected to be influenced to embrace the concept personally. Therefore, the notion that CSR facilitated some form of personal growth in the area of giving back to society further suggests that this influence can even extend outside the workplace in developing employee skills.

The ability for employees to personally advance and progress through the benefits of CSR initiatives could be seen to generate a feeling of indebtedness amongst workers. While only expressed by a minority of respondents, this feeling can be seen to culminate in a sense of loyalty to the organisation that has invested in the development and growth of its employees. Existing literature has recognised the manner in which the employee perceives the organisation has the ability to influence turnover and staff retention (Riordan et al., 1997). This view was reflected by respondents in this study where, the more an employee perceived the organisation is concerned with the advancement of their skills, the more that they are likely to want to reciprocate the investment made in them. That is, the opportunity for employees to develop skills through the implementation of CSR activities can enable them to feel valued by the organisation and therefore increase their loyalty to it.

Ultimately this sense of loyalty can lead to the increase in an employee's sense of belonging. The responses suggest that the more an employee is loyal to the organisation, the more they are able to identify and align with the company. As identified by previous literature, in doing so, the employee can build a bond or connection with the organisation that establishes a sense of belonging and thus influences the length of an employee's membership (Ghafoor et al., 20110; Fu et al., 2014). Furthermore, as the loyalty is largely a result of feeling valued, this is likely to increase an employee's sense of acceptance within the organisation which 
again strengthens their sense of belonging. This is largely reflective of existing research that emphasised employees' desire to feel significant and worthy at work as a part of attaining a sense of belonging (Ferris et al., 2009). Therefore, similar to Loop One, this loop depicts a virtuous cycle whereby the positive implications of CSR activities are seen to flow onto a sense of belonging.

\subsection{Loop Three: Overleveraging the Value of CSR}

Loops One and Two illustrate distinct complementarities identified from participant's responses and each concludes similarly, with the positive effects on their sense of belonging. Such a portrayal is widely reflective of the general consensus among respondents where CSR activities were perceived as having an overall positive impact. While this was the view of the majority, a few responses also recognised the potential for adverse impacts to diminish this effect.

This possibility of negative consequences is recognised in the existing literature as being most commonly driven by the suspicion employees' harbour in regards to the underlying motives behind CSR (De Roeck et al., 2014). Correspondingly, responses here also alluded to the motivations of CSR by emphasising the importance of genuineness in its implementation and the negative circumstances that may arise if this authenticity was compromised. With previous studies demonstrating the effectiveness and capacity of CSR to enhance a company's image among its external stakeholders and the general public, it follows that corporates are increasingly enticed to capitalise on its value (Strand et al., 1981).

Consequently, there is the potential for increased awareness of CSR to result in overleveraging its value with external stakeholders. The more CSR is communicated and made known throughout the organisation therefore, is likely to increase the levels of publicity and external promotion that is associated with the initiatives. Furthermore, the more knowledgeable an employee is of the CSR practices, the more they will be able to discern if initiatives are being implemented for profit-driven reasons.

This notion of overleveraging the CSR initiatives was identified by respondents as having the potential to fuel cynicism amongst employees. CSR has often received criticism as a marketing tool that only seeks the profits for the company and has been identified and labelled as greenwashing (Strand et al., 1981). Greater public promotion and advertising of CSR initiatives have been identified as being detrimental to the genuineness and authenticity 
of initiatives. Despite participants identifying their desire for the awareness of CSR, they also stated that there were negative effects of excessive publicity. In doing so, a paradox of CSR is revealed where such initiatives are increasingly desired, yet over promotion is perceived negatively as purely a marketing strategy. This paradox, identified in the literature review, was specifically applied to the reactions and responses of consumers and the public (Morsing, Schultz, \& Nielsen, 2008). However, its identification by respondents indicates its applicability and relevance to employees and thus suggests the potential for a vicious cycle to be created as a result. The more an employee believes the organisation is undertaking CSR initiatives purely for profit-driven purposes, the less they can feel inclined to identify with the company. With the responses indicating that genuine intentions are as important as the initiatives themselves, an employee's sense of belonging can be adversely influenced. Therefore, it can be understood that the CSR activities of the company has the potential to backfire and create a subsequent downwards spiral for an employee's sense of belongingness. While this negative response was identified by comparatively fewer respondents, it can be seen has holding the potential to overpower the positive implications.

\subsection{Limitations and Implications for Future Research}

This thesis was focused on generating understanding of the nature and extent of the relationship between CSR and an individual employee's sense of belonging. The information gathered and resulting findings have facilitated a greater and more holistic understanding of this relationship. However, there are limitations of the study that need to be noted. Certain constraints, specific to the methodological approach undertaken were discussed in previous chapters. Yet, there are additional limitations that need to be acknowledged although they do provide some future research opportunities.

While this study was focused on the influence of CSR on an employee's sense of belonging, it could not fully examine the potential for other contextual and demographic factors to contribute to a worker's attachment to the organisation. However, this was taken into consideration and the study sought to gain a wide range of employees from the organisation to account for the various backgrounds and differences of individuals. The researcher's ability to achieve this was limited to a certain extent by the agreement with the organisation selected for the study. Consent was gained from management to interview employees with the understanding that the organisation would take responsibility for selecting the 
participants to be involved. Although a range of respondents was specified and asked for, ultimately the participants were asked by management to volunteer for involvement in the study thereby restricting control over the spread of respondents involved. As a result, the variety documented was essentially based on luck and accordingly there was a relative over representation of women and lower level employees as this was the demographic that more readily volunteered to participate. This limitation could not be eliminated or minimised without compromising the wishes of the organisation. Ultimately, while some demographics may have been more represented than others, it was not considered a significant obstacle with the study still gaining a sufficiently diverse sample.

Furthermore, while this study reported the diversity of respondents and their backgrounds, their effect on the data about the relationship between CSR and belonging could not be analysed. Thus, future research may extend this research by exploring the extent to which such factors affect and impact upon the capability of CSR to influence a sense of belonging. For example, the length of time an employee spent at a company or their position within the organisational hierarchy may have significant bearing over the extent to which an individual feels an attachment to the company. The findings of this study can conclude that a positive relationship can be achieved between CSR and employee belongingness but future studies have the potential to extend this further and explore how and/or the extent to which demographics and personal backgrounds can impact on the nature of this relationship.

Understanding this relationship between CSR and employee belonging was the focus of the research, as per the research question. However, there was no attempt made to expressly test the relationship. The qualitative method undertaken met the purposes of this study, however, it did not allow for correlations to be made and test the strength of the relationship. This therefore, presents future studies with the opportunity to extend this research by further exploring the relationship examined in this study. The findings should enable greater understanding of the relationship so that future studies are able to explore its generalisability through quantification. Studying this relationship in other organisations and sectors will also be important to ascertain if other factors may impact the linkages reported here. 


\subsection{Managerial Implications}

With this study being predominantly focused on the relationship between CSR and an employee's sense of belonging, there are various insights gathered that can be undertaken by management to enhance this relationship and ultimately benefit the company. It has already been identified that employees are a relatively unexplored area in terms of CSR and as such, the potential benefits that could originate from their involvement have been similarly overlooked. This thesis concludes that an opportunity is available for organisations to enhance employee's sense of belonging and ultimately, overall employee relations through the implementation of CSR. Specifically focusing on the relationship between CSR and a sense of belonging has unearthed findings that provide numerous implications for organisations to capitalise on. While this study was focused on a single organisation in Wellington, New Zealand, the understanding developed appears to hold the potential for application to a range of organisations nationwide and even internationally. However, each organisation is undeniably different with unique characteristics and must be treated accordingly.

While the framework developed in previous sections illustrates the numerous factors and their interdependencies that ultimately lead to an enhanced sense of belonging, management can benefit from the employee involvement reflected in these connections. The significance of employee participation has been identified in previous chapters with existing literature recognising its ability to fulfil higher order needs and facilitate an increased level of identification (Kim et al., 2010). Consequently, endorsing and promoting employee involvement throughout CSR strategy can be seen as an essential prerequisite to ensure the benefits of achieving employee belongingness are reaped.

Introductory chapters discussed the adoption of employee volunteer days amongst the local and national community. Such initiatives that actively encourage and promote employee participation in company CSR efforts are one of the numerous ways management and organisational leaders can facilitate greater levels of involvement. Through the promotion of employee involvement in CSR, management allows individuals to be part of something greater and collectively achieve benefits towards society. As such, they are able to satisfy an individual's sense of belonging as well as reap the benefits that are expected to eventuate towards the organisation. 
However, while CSR has been understood as having the potential to positively influence a sense of belonging, companies must carefully consider their approach to facilitating employee buy-in. For example, the effectiveness of staff volunteer programs mentioned above has also been validated in existing literature that recognises its ability to increase employee identification (Bauman \& Skitha, 2012). Yet despite this, compelling workers to partake in activities and initiatives that are of no interest or value to the individual could negate any potential benefits to both the individual and the company as a whole. As a result, management are faced with balancing the approaches to ensure desirable outcomes are achieved.

In attempting to successfully achieve this balance, organisations are able to refer to the idea of employee-driven initiatives. Management may be able to facilitate greater involvement by tailoring CSR practices to the needs and values of its employees and thus voluntarily engage employees throughout its initiatives. Employees are more likely to become involved in practices that leads to benefits in what they hold dear and allows for a deeper bond to be forged with their organisation.

\subsection{Conclusion}

In conclusion, this study provides useful novel insight into the previously under researched relationship between CSR and an employee's sense of belongingness. With employees as a stakeholder in CSR gradually becoming more prominent throughout literature, this study sought to address a relationship, and its repercussions, that have been somewhat overlooked. CSR remains a dynamic concept whose influence over organisational stakeholders and the general public is increasingly gaining more momentum. Similarly, a sense of belonging in the workplace is becoming a more apparent desire amongst workers and an inherent goal of organisations. This study therefore presents an initial step towards understanding the relationship between these two concepts and the ability of CSR to influence and instil this sense of belonging within an employee. The findings facilitate deeper levels of understanding of the very real potential of a company to foster belongingness through the implementation of CSR across the organisation. However it also points towards the future research opportunities to expand and build on this understanding via testing and quantifying this relationship. 


\section{REFERENCES}

3News New Zealand. (2012, October 5). Greens: Foreign-owned banks make too much money. Retrieved from 3News : http://www.3news.co.nz/politics/greens-foreignowned-banks-maketoo-much-money-2012100512\#axzz3SbymYasu

Aguilera, R. V., Rupp, D. E., Williams, C. A., Ganapathi, \& J. (2007). Putting the S back in Corporate Social Responsibility: A multilevel theory of Social Change in Organisations . Academy of Management Review , 32(3), 836-863.

Aguinis, H. (2011). Organisational Responsibility: Doing Good and Doing Well. In Zedeck, Sheldon (Eds), APA Handbok of Industrial and Organisational Psychology (pp. Vol 3, 855-879). Washington DC: American Psychological Association .

Alam, S., \& Rizvi, K. (2012). Psychological Well-Being Among Bank Employees . Journal of the Indian Academy of Applied Psychology , 38(2), 242-247.

Albinger, H., \& Freeman, S. (2000). Corporate Social Performance and Attractiveness as an Employer to Different Job Seeking Populations . Journal of Business Ethics , 28(30), 243-253.

Anant, S. (1967). Belongingness and Mental Health: Some Research Findings . Acta Psychology, 26, 391-396.

ANZ. (2015, March 02). Corporate Responsibillity - Volunteering. Retrieved from ANZ: http://www.anz.co.nz/about-us/corporate-responsibility/community/volunteering/

ASB. (2014). Corporate Social Responsibility Report. New Zealand : ASB.

Aupperle, K., Carroll, A., \& Hatfield, J. (1985). An Empirical Examination of the Relationship Between Corporate Social Responsibility and Profitability . Academy of Management Journal , 28(2), 446-463.

Australian Centre for Corporate Social Responsibility . (2014). The 10th Year - Progress and Prospects for CSR in Australia and New Zealand. Docklands, VIC : Australian Centre for Corporate Social Responsibility .

Bashir, R., Hassan, A., \& Cheema, F. (2012). Impact of Corporate Social Responsibility Activities over the Employees of the Organisations: An Exploratory Study . Journal of Management and Social Sciences , 8(2) 11-21.

Bauman, C. W., \& Skitha, L. J. (2012). Corporate Social Responsibility as a Source of Employee Satisfaction . Research in Organisational Behaviour , 32, 63-68.

Benson, S., \& Dundis, S. (2003). Understanding and Motivating Health Care Employees: Integrating Maslow's Hierachy of Needs, Training and Technology. Journal of Nursing Management , 11, 315-320.

Berg, B., \& Lune, H. (2012). Qualitative Research Methods for the Social Sciences (ed 8). New Jersey : Pearson Education Inc. . 
Berry, J. (2014). Y in the Workplace: Comparative Analysis of Values, Skills and Perceptions of Government Communication Amongst University Students and Government Staff . Foresight , 16(5), 432-447.

bnz. (2015, March 9). Supporting our Communities . Retrieved from bnz : https://www.bnz.co.nz/about-us/sustainability/supporting-our-communities

Bollard, A., Ng, \& T. (2014). Learnings from the Global Financial Crisis . Reserve Bank of New Zealand: Bulletin , 75(3), 57-66.

Brammer, S., Millington, A., \& Rayton, B. (2007). The Contribution of Corporate Social Responsibility to Organisational Commitment. The International Journal of Human Resource Management, 18, 1701-1719.

Braun, V., \& Clarke, V. (2006). Using Thematic Analysis in Psychology . Qualitative Research in Psychology , 3, 77-101.

Carr, L. (1994). The Strengths and Weaknesses of Quantitative and Qualitative Research: What Method for Nursing? Journal of Advanced Nursing , 20, 716-721.

Carroll, A. (1979). A Three-Dimensional Conceptual Model of Corporate Performance . Academy of Management Review, 4(4), 497-505.

Carroll, A. (1991). The Pyramid of Corporate Social Responsibility: Toward the Moral Management of Organisational Stakeholders . Business Horizons , 34(4), 39-48.

Carroll, A. (1999). Corporate Social Responsibility: Evolution of a Definitional Construct . Business and Society , 38(3) 268-295.

Carroll, A., \& Shabana, K. (2010). The Business Case for Corporate Social Responsibility: A Review of Concepts, Reserach and Practice . International Journal of Manament Reviews , 12(1), 85105.

Chong, M. (2009). Employee Participation in CSR and Corporate Identity: Insights from a DisasterResponse Program in the Asia-Pacific . Corporate Reputation Review , 12(2), 106-119.

Ciprian-Dumitru, S. (2013). How to Deal with Corporate Social Responsibility Related to Employees . Annals of Faculty of Economics ,1(1), 1675-1681.

Claessens, S., Dell'Ariccia, G., Igan, D., \& Laeven, L. (2010). Cross-Country Experiences and Policy Implications fromthe Global Financial Crisis . Economic Policy , 25(62), 267-293.

Clark, C. (2000). Differences Between Public Relations and Corporate Social Responsibility: An Analysis . Public Relations Review , 26(3), 363-380.

Clarkson, M. (1995). A Stakeholder Framework for Analysing and Evaluating Corporate Social Performance . Academy of Management Review , 20(1), 92-117.

Cockshaw, W., Shochet, I., \& Obst, P. (2013). General Belongingness, Workplace Belongingess, and Depressive Symptoms. Journal of Community and Applied Social Psychology , 23, 240-251.

Collier, J., \& Esteban, R. (2007). Corporate Social Responsibility and Employee Commitment . Business Ethics: A European Review , 16(1), 19-33.

Coyne, I. (1997). Sampling in Qualitative Research. Purposeful and Theoretical Sampling; Merging or Clear Boundaries? Journal of Advanced Nursing , 26, 623-630. 
Crotty, J. (2009). Structural Causes of the Global Financial Crisis: A Critical Assessment of the 'New Financial Architecture'. Cambridge Journal of Economics , 33, 563-580.

Dawkins, J., \& Lewis, S. (2003). CSR in Stakeholder Expectations: And Their Implication for Company Strategy. Journal of Business Ethics, 44(2/3), 185-193.

De Cremer, D., \& Blader, S. (2006). Why do People care about Procedural Fairness? The Importance of Belongingness in Responding and Attending to Procedures . European Journal of Social Psychology , 36, 211-228.

De Roeck, K., \& Delobbe, N. (2012). Do Environmental CSR Initiatives Serve Organisations' Legitimacy in the Oil Industry? Exploring Employee's Reactions Through Organisational Identification Theory . Journal of Business Ethics , 110(4), 397-412.

De Roeck, K., Marique, G., Stinglhamber, F., \& Swaen, V. (2014). Understanding Employees' Responses to Corporate Social Responsibility: Mediating Roles of Overall Justice and Organsiational Identification. The International Journal of Human Resource Management , 25(1) 91-112.

Dermiguc-Kunt, A., \& Huizinga, H. (1999). Determinants of commercial bank interest margins and profitability: Some international evidence. The World Bank Economic Review , 13(2), 379-408.

Ellis, A. (2009). The Impact of Corporate Social Responsibility on Employee Attitudes and Behaviours . Academy of Management , 14, 1-6.

Eweje, G., \& Bentley, T. (2006). CSR and Staff Retention in New Zealand Companies: A Literature Review . Department of Management and International Business , 6.

Farooq, M., Farooq, O., \& Jasimuddin, S. (2014). Employees Response to Corporate Social Responsibility: Exploring the Role of Employees' Collectivist Orientation . European Management Journal , 32(6), 916-927.

Ferris, D., Brown, D., \& Heller, D. (2009). Organisational supports and Organisational Deviance: The mediating role of organisation-based self-esteem . Organisational Behaviour and Human Decision Processes , 108 279-286.

Fletcher, S. (2014). The Occupy Movement . In S. Maile, \& D. Griffiths, Public Engagement and Social Science (pp. 83-95). Bristol : Policy Press .

Fong, A. (2014, December 2). WestJet Airlines Ltd takes its heartwarming 'Christmas Miracle' video to Dominican Republic community. Retrieved from Financial Post : http://business.financialpost.com/2014/12/02/westjet-airlines-ltd-takes-its-heartwarmingchristmas-miracle-video-to-dominican-republic-community/

Fossey, E., Harvey, C., McDermott, F., \& Davidson, L. (2002). Understanding and Evaluating Qualitative Research . Australian and New Zealand Journal of Psychiatry , 36, 717-732.

Friedman, M. (1970, Septemeber 13). The Social Responsibility of Businesses is to Increase its Profits . The New York Times Magazine .

Friedman, M. (2002). The Social Responsibility of Business is to Increase its Profits. In R. Chadwick, \& D. Schroeder, Applied Ethics: Critical Concepts in Philosophy (Volume 5) (pp. 57-63). London : Routeledge.

Fu, H., Haobin, Y., \& Law, R. (2014). You do well and I do well? The Behavioural Consequences of Corporate Social Responsibility . International Journal of Hospitality Management, 40, 62-70. 
Ghafoor, A., Masood, T., Khan, A., \& Hijazi, S. (2011). Transformational Leadership, Employee Engagement and Performance: Mediating Effect of Psychological Ownership. African Journal of Business Management , 51(17), 739-7403.

Gond, J., El-Akremi, A., Igalens, J., \& Swaen, V. (2010). Corporate Social Responsibility Influence on Employees. Nottingham : International Centre for Corporate Social Responsibility .

Gray, R., Kouhy, R., \& Lavers, S. (1995). Corporate Social and Environmental Reporting . Accounting, Auditing and Accountability Journal , 8(2), 47-77.

Hackston, D., \& Milne, M. (1996). Some Determinants of Social and Environmental Disclosures in New Zealand Companies. Accounting, Auditing and Accountability Journal, 9(1) 77-108.

Hagerty, B., \& Patusky, K. (1995). Developing a Measure of Sense of Belonging . Nursing Reserach , 44(1), 9-13.

Hagerty, B., Lynch-Sauer, J., Patusky, K., Maria Bouwsema, M., \& Collier, P. (1992). Sense of Belonging: A Vital Mental Health Concept. Archives of Psychiatric Nursing, 6(3) 172-177.

Halme, M., \& Laurila, J. (2009). Philanthropy, Integration or Innovation? Exploring the Financial and Societal Outcomes of Different Types of Corporate Responsibility . Journal of Business Ethics, 84, 325-339.

Harris, P. (2007). We The People: The Importance of Employees in the Process of Building Customer Experience . Brand Management , 15(2), 102-114.

Holliday, A. (2007). Doing and Writing Qualitative Research (2nd ed). London : Sage Publications Inc.

Holstein, J., \& Gubrium, J. (2004). The Active Interview . In D. Silverman, Qualitative Research: Theory, Method and Practice (2nd ed) (pp. 140-161). London : Sage Publications Inc. .

Hornsey, M., \& Jetten, J. (2004). The Individual Within the Group: Balancing the Need to Belong with the Need to be Different . Personality and Social Psychology Review , 8(3), 248-264.

Jacelon, C., \& O'Dell, K. (2005). Analysing Qualitative Data . Urologic Nursing , 25(3), 217-220.

Jacinto, A., \& Carvalho, I. (2009). Corporate Social Responsibility: The Influence of Organisational Practices Perceptions in Employee's Performance and Organisational Identification. In E. Morin, N. Ramalho, J. Neves, \& A. (. Savoie, New Research Trends in Effectiveness, Health and Work: A Criteos Scientific and Professional Account (pp. 175-204). Montreal, Canada: Criteos/HEC-Montreal .

Jamali, D. (2006). Insights into Triple Bottom Line Integration from a Learning Organisation Perspective . Business Process Management Journal , 12(6), 809-821.

Jenkins, R. (2014, November 28). So Banks are too Big to Fail. Are they also too big to regulate? . Retrieved from The Guardian :

http://www.theguardian.com/commentisfree/2014/nov/28/banks-too-big-to-fail-regulatefinancial-sector-accountability

Jones, B., Bowd, R., \& Tench, R. (2009). Corporate Irresponsibility and Corporate Social Responsibility: Competing Realities . Social Responsibility Journal , 5(3), 300-310.

Joyner, B., \& Payne, D. (2002). Evolution and Implementation: A Study of Values, Business Ethics and Corporate Social Responsibility . Journal of Business Ethics , 41, 297-311. 
Kim, H., Lee, M., Lee, H., \& Kim, N. (2010). Corporate Social Responsibiltiy and Employee-Company Identification . Journal of Business Ethics, 95, 557-569.

King, N. (2004). Using Template in the Thematic Analysis of Text. In G. Symon, \& C. Cassell, Essential Guide to Qualitative Methods in Organisational Research (pp. 256-270). London : Sage Publications .

King, N. (2012). Doing Template Analysis . In G. Symon, \& C. Cassell, Qualitative Organisational Research: Core Methods and Current Challenges (pp. 426-450). London : Sage Publications .

Kiwibank . (2015, March 9). Our People: Benefits . Retrieved from Kiwibank : https://workforus.kiwibank.co.nz/our-people/benefits

KPMG. (2013). The KPMG Survey of Corporate Responsibility Reporting 2013. Netherlands : KPMG International Cooperative .

Lambert, N., Stillman, T., Hicks, J., Kamble, S., Baumeister, R., \& Fincham, F. (2013). To Belong is to Matter: Sense of Belonging Enhances Meaning in Life . Personality and Social Psychology Bulletin , 39(11) 1418-1427.

Langman, L. (2013). Occupy: A New Social Movement . Current Sociology , 61(4), 510-524.

Lee, R., \& Robbins, S. (1995). Measuring Belongingness: The Social Connectedness and the Social Assurance Scales . Journal of Counselling Psychology , 42(2), 232-241.

Lee, R., \& Robbins, S. (1998). The Relationship Between Social Connectedness and Anxiety, SelfEsteem, and Social Identity . Journal of Counselling Psychology , 45(3), 338-345.

Lee, R., Keough, L., \& Sexton, J. (2002). Social Connectedness, Social Appraisal, and Perceived Stress in College Women and Men . Journal of Counselling and Development , 80, 355-361.

Lee, Y., Choi, J., Moon, B., \& Babin, B. (2014). Codes of Ethics, Corporate Philanthropy, and Employee Responses . International Journal of Hospitality Management , 39, 97-106.

Lee, Y., Kim, S., Lee, K., \& Li, D. (2012). The Impact of CSR on Relationship Quality and Relationship Outcomes: A Perspective of Service Employees. International Journal of Hospitality Management , 31, 745-756.

Levett-Jones, T., \& Lathlean, J. (2009). The Ascent to Competence Conceptual Framework: An Outcome of a Study of Belongingness . Journal of Clinical Nursing , 18, 2870-2879.

Logsdon, J., \& Lewellyn, P. (2000). Expanding Accountability to Stakeholders: Trends and Predictions . Business and Society Review , 105(4), 419-435.

Marshall, C., \& Rossman, G. (2006). Designing Qualitative Research (4th ed). Thousand Oaks, CA: Sage Publications Inc.

Marshall, M. (1996). Sampling for Qualitative Research. Family Practice, 13(6), 522-525.

Martin, C. (2005). From High Maintenance to High Productivity: What Managers Need to Know About Generation Y . Industrial and Commercial Training , 37(1), 39-44.

Mason, J. (2003). Qualitative Researching (2nd ed). London : Sage Publications .

Mathieson, D. (1980). Financial Reform and Stabilisation Policy in a Developing Economy . Journal of Development Economics , 7, 359-395. 
McWilliams, A., \& Siegel, D. (2001). Corporate Social Responsibility: A Theory of the Firm Perspective. Academy of Management Review, 26(1), 117-127.

McWilliams, A., \& Siegel, D. (2001). Corporate Social Responsibility: A THeory of the Firm Perspective . Academy of Management Review , 26(1), 117-127.

Miles, M., Huberman, A., \& Saldana, J. (2014). Qualitative Data Analysis: A Methods Sourcebook (ed. 3). Thousand Oaks, CA: Sage Publications .

Miller, J., \& Glassner, B. (2004). The "inside" and the "outside". Finding Realities in Interviews. In D. Silverman, Qualitative Research: Theory, Method and Practice (2nd ed) (pp. 125-139). London : Sage Publications Inc. .

Morsing, M. (2006). Corporate Social Responsibility as Strategic Auto-Communication: On the Role of External Stakeholders for Member Identification . Business Ethics: A European Review , 15(2), 171-182.

Morsing, M., Schultz, M., \& Nielsen, K. (2008). The 'Catch 22' of Communicating CSR: Findings from a Danish Study . Journal of Marketing Communications , 14(2), 97-111.

Mutzabaugh, B. (2014, December 2). WestJet's 2014 'Christmas Miracle' comes to Dominican Republic. Retrieved from USA Today : http://www.usatoday.com/story/todayinthesky/2014/12/02/westjets-christmas-miraclecomes-to-dominican-republic/19777473/

Norman, R. (2011, November 2). Aussie banks continue to post record profits (and send them offshore).

Norman, W., \& MacDonald, C. (2004). Getting to the Bottom of "Triple Bottom Line" . Business Ethics Quarterly, 14(2), 243-262.

Occupy Together . (2015, March 11). Learn About Occupy . Retrieved from Occupy Together : http://www.occupytogether.org/aboutoccupy/

O'Leary. (2004). The Essential Guide to Doing Your Research Project . London: Sage Publications .

Patton, M. (2002). Two Decades of Developments in Qualitative Inquiry . Qualitative Social Work: Research and Practice , 1(3), 261-283.

Peterson, D. (2004). The Relationship Between Perceptions of Corporate Citizenship and Organisational Commitment . Business and Society , 43, 296-319.

Porter, M., \& Kramer, M. (2006). Strategy and Society: The Link Between Competitive Advantage and Corporate Social Responsibility . Harvard Business Review , 84(12), 78-92.

Prieto-Carron, M., Lund-Thomsen, P., Chan, A., Muro, A., \& Bhushan, C. (2006). Critical Perspectives on CSR and Development: What we know, What we don't know and What we need to know . International Affairs , 82(5), 977-987.

Ramasamy, B., \& Yeung, M. (2009). Chinese Consumers' Perception of Corporate Social Responsibility (CSR). Journal of Business Ethics , 88, 119-132.

Rego, A., Cunha, M., \& Souto, S. (2009). Does the Need to Belong Moderate the Relationship Between Perceptions of Spirit Camaraderie and Employees' Happiness? Journal of Occupational Health Psychology , 14(2), 148-164. 
Reserve Bank of New Zealand . (2004, August). Proposals for closer integration of trans-tasman banking regulation and supervision. Retrieved from RBNZ:

http://www.rbnz.govt.nz/regulation_and_supervision/banks/relationships/0163830.html

Riordan, C., Gatewood, R., Bill, \& J. (1997). Corporate Image: Employee Reactions and Implications for Managing Corporate Social Performance . Journal of Business Ethics , 16, 401-412.

Rodrigo, P., \& Arenas, D. (2008). Do Employees Care About CSR Programs? A Typology of Employees According to their Attitudes. Journal of Business Ethics, 83, 265-283.

Rupp, D., Ganapathi, J., Aguilera, R., \& Williams, C. (2006). Employee Reactions to Corporate Social Responsibility: An Organisational Justice Framework . Journal of Organisational Behaviour, 27, 537-543.

Rupp, D., Skarlicki, D., \& Shao, R. (2013). The Psychology of Corporate Social Responsibility and Humanitarian Work: A Person-Centric Perspective . Industrial and Orgaisational Psychology , 6(4), 361-368.

Russo, A., \& Perrini, F. (2009). Investigating Stakeholder Theory and Social Capital: CSR in Large Firms and SME's. Journal of Business Ethics, 91, 207-221.

Sachs, S., Maurer, M., Ruhli, E., \& Hoffmann, R. (2006). Corporate Social Responsibility from a "Stakeholder View" Perspective: CSR Implementation by a Swiss Moblie Telecommunication Provider . Corporate Governance , 4, 506-515.

Sale, J., Lohfeld, L., \& Brazil, K. (2002). Revisiting the Quantitative-Qualitative Debate: Implications for Mixed-Methods Research . Quality and Quantity , 36, 43-53.

Sandelowski, M. (1986). The Problem of Rigor in Qualitative Research . Advances in Nursing Science, $8(3), 27-37$.

Sandelowski, M. (1995). Sample Size in Qualitative Research . Research in Nursing and Health , 18, 179-183.

Scherer, A., \& Palazzo, G. (2009). Globalisation and Corporate Social Responsibility. In A. Crane, A. McWilliams, D. Matten, J. Moon, \& D. Siegal, The Oxford Handbook of Corporate Social Responsibility (pp. 413-431). New York : Oxford University Press.

Schwartz, M., \& Carroll, A. (2003). Corporate Social Responsibility: A Three-Domain Approach . Business Ethics Quarterly , 13(4), 503-530.

Shuttleworth, K. (2012, October 5). Australian-owned trading banks thriving after financial crisis. Retrieved from The New Zealand Herald :

http://www.nzherald.co.nz/business/news/article.cfm?c_id=3\&objectid=10838595

Skudiene, V., \& Auruskeviciene, V. (2012). The Contribution of Corporate Social Responsibility to Internal Employee Motivation . Baltic Journal of Management , 7(1), 49-67.

Statistics New Zealand . (2014). New Zealand's Inward Foreign Affiliate Statistics. Wellington: Statistics New Zealand.

Stawiski, S., Deal, J., Gentry, W., \& Rweyongoza, S. (2011). Employee Perceptions of Corporate Social Responsibility: The Implications for Your Organisation. Greensboro, NC: Centre for Creative Leadership. 
Strand, R., Levine, R., \& Montgomery, D. (1981). Organisational Entry Preferences Based Upon Social and Personnel Policies: An Information Integration Perspective . Organisational Behaviour and Human Decision Processes , 27, 50-68.

Strautmanis, J. (2008). Employees' Value Orientation in the Context of Corporate Social Responsibility . Baltic Journal of Management , 3(3), 346-358.

The Economist . (2006, November 25). Special Report: A Heavyweight Champion, at Five Foot Two Milton Friedman. The Economist, p. 108.

The Reserve Bank of New Zealand . (2014, November 18). Register of Registered Banks in New Zealand. Retrieved from The Reserve Bank of New Zealand : http://www.rbnz.govt.nz/regulation_and_supervision/banks/register/

Treasury, N. Z. (2007, October). New Zealand Financial Markets, Savings and Investment. Retrieved from The New Zealand Treasury: http://www.treasury.govt.nz/publications/researchpolicy/ppp/2007/07-01

Turker, D. (2009). Measuring Corporate Social Responsibility: A Scale Development Study . Journal of Business Ethics , 85, 411-427.

Van Prooijen, J., Wilke, H., \& Van de Bos, K. (2004). Group Belongingness and Procedural Justice: Social Inclusion and Exclusion by Peers Affects the Psychology of Voice . Journal of Personality and Social Psychology , 87(1), 66-79.

Visser, W. (2005). Revisiting Carroll's CSR Pyramid: An African Perspective . In E. Pederson, \& M. (. Huniche, Corporate Citizenship in a Development Perspective (pp. 29-56). Copenhagen : Copenhagen Business School Press .

Votaw, D. (1972). Genius Became Rare: A Comment on the Doctrine of Social Responsibility. California Management Review, 15(2), 25-31.

Waring, T., \& Wainwright, D. (2008). Issues and Challenges in the Use of Template Analysis: Two Comparative Case Studies from the Field . Electronic Journal of Business Research Methods, 6(1), 85-94.

Werther, W., \& Chandler, D. (2005). Strategic Corporate Social Responsibility as Global Brand Insurance . Business Horizons , 48(4), 317-324.

Westpac NZ. (2015, March 02). Volunteering Programs. Retrieved from Westpac NZ: http://www.westpac.co.nz/who-we-are/sustainability-and-community/contributing-to-ourcommunities/making-a-difference-locally/volunteering-programmes/

World Business Council for Business Development . (2015, March 07). New Zealand Sustainable Business Council (NZ SBC) . Retrieved from World Business Council for Business Development : http://www.wbcsd.org/regional-network/members-list/oceania/nzbcsd.aspx

Wu, S., Wang, \& W. (2014). Impact of CSR Perception on Brand Image, Brand Attitude and Buying Willingness: A Study of a Global Cafe . International Journal of Marketing Studies , 6(6), 4356.

Zhu, Q., Yin, H., Liu, J., \& Lai, K. (2014). How is Employee Perception of Organisational Efforts in Corporate Social Responsibility Related to their Satisfaction and Loyalty Towards Developing Harmonious Society in Chinese Enterprises? . Corporate Social Responsibility and Environmental Management , 21, 28-40. 


\section{APPENDIX 1: INTERVIEW STRUCTURE}

\section{Semi-Structured Interview Schedule}

The interviews, approximately half an hour long, will be conducted in a semi-structured manner so as to guide the respondents whilst simultaneously allowing them the opportunity to expand on their ideas or opinions and provide a wider range of insight.

Below is an outline of questions that will enable the interview to be structured to a certain extent and ensure certain questions are asked.- The broader ideas and issues are of the most importance with the questions there to simply provide guidance to the interview.

The following broad structure is adapted from, and based on the interview protocol undertaken in Rodrigo and Arenas research concerning employee reactions to CSR. (Rodrigo \& Arenas, 2007). As per the methodology chosen for this research, this interview is conducted in a manner that allows respondents to wander in different directions so as to collect deeper insight and understanding.

Section One: General and Introductory
a) Name and age?
b) Current position within the company and what that entails?
c) Length of time spent as an employee at the organisation?
d) What initially attracted you to this company?
e) In what ways do you feel a part of or included in your organisation?
f) How important to you is this sense of belonging to your organisation?

Section Two: General knowledge and understanding concerning Corporate Social Responsibility (CSR)
a) What is your understanding of CSR? (What it means, what it entails?)
b) How important do you think CSR is and why?
c) What are your views on companies carrying out CSR activities?

Section Three: CSR and employee reactions

a) Can you explain some of the practices that your company has undertaken which you believe to be an aspect of CSR?

b) How do these actions impact on you as an employee? 